\title{
EXPERIMENTAL AND THEORETICAL MODELING OF DIAMONDIFEROUS PLUMES
}

\author{
A. G. Kirdyashkin1, A. A. Kirdyashkin'1, 2, V. E. Distanov¹, I. N. Gladkov¹ \\ 1 V.S. Sobolev Institute of Geology and Mineralogy, Siberian Branch of RAS, Novosibirsk, Russia \\ ${ }^{2}$ Novosibirsk State University, Novosibirsk, Russia
}

\begin{abstract}
We consider thermochemical mantle plumes with thermal power $1.6 \cdot 10^{10} \mathrm{~W}<N<2.7 \cdot 10^{10} \mathrm{~W}$ (relative thermal power $1.15<\mathrm{Ka}<1.9$ ) as plumes with an intermediate thermal power. Such plumes are formed at the core-mantle boundary beneath cratons in the absence of horizontal free-convection mantle flows beneath them, or in the presence of weak horizontal mantle flows. A proposed scheme of convection flows in the conduit of a plume with an intermediate thermal power is based on laboratory and theoretical modeling data. A plume ascends (melts out) from the coremantle boundary to critical depth $x_{к р}$ from which magma erupts on the Earth's surface. The magmatic melt erupts from the plume conduit onto the surface through the eruption conduit. The latter forms under the effect of superlithostatic pressure on the plume roof. While the thickness of the block above the plume roof decreases to a critical value $x_{\mathrm{kp}}$, the shear stress on its cylindrical surface reaches a critical value (strength limit) $\tau_{\mathrm{\kappa p}}$.Rock fails in the vicinity of the cylindrical block and, as a consequence, the eruption conduit is formed. We estimate the height of the eruption conduit and the time for the plume to ascent to the critical depth $\chi_{\mathrm{\kappa} p}$. The volume of erupted melt is estimated for kinematic viscosity of melt $v=0.5-2 \mathrm{~m}^{2} / \mathrm{c}$. The depth $\Delta x$ from which the melt is transported to the surface is determined. Using the eruption volume, we obtain a relationship between the depth $\Delta x$ and the plume conduit diameter for the above-mentioned kinematic viscosities. In the case that the depth $\Delta x$ is larger than $150 \mathrm{~km}$, the melt from the plume conduit can transport diamonds to the Earth's surface. Thus, the plumes with an intermediate thermal power are diamondiferous. The melt flow structure at the plume conduit/eruption conduit interface is determined on the basis of the laboratory modeling data. The photographs of the simulated flow were obtained. The flow line velocities were measured in the main cylindrical conduit (plume conduit) and at the main conduit/eruption conduit interface. A stagnant area is detected in the 'conduit wall/plume roof' interface zone. The melt flow in the eruption conduit was analyzed as a turbulent flow in the straight cylindrical conduit with diameter $d_{\mathrm{K}}$. According to the experimental modeling and theoretical data, the superlithostatic pressure in the plume conduit is the sum of the frictional pressure drop and the increasing dynamic pressure in the eruption conduit. A relationship between the melt flow velocity in the eruption conduit and superlithostatic pressure has been derived.
\end{abstract}

Key words: thermochemical plume; thermal power; free-convection flows; melt; superlithostatic pressure; flow velocity; eruption conduit

For citation: Kirdyashkin A.G., Kirdyashkin A.A., Distanov V.E., Gladkov I.N., 2019. Experimental and theoretical modeling of diamondiferous plumes. Geodynamics \& Tectonophysics 10 (2), 247-263. doi:10.5800/GT-2019-10-2-0413. 


\title{
ЭКСПЕРИМЕНТАЛЬНОЕ И ТЕОРЕТИЧЕСКОЕ МОДЕЛИРОВАНИЕ АЛМАЗОНОСНЫХ ПЛЮМОВ
}

\author{
А. Г. Кирдяшкин ${ }^{1}$, А. А. Кирдяшкин ${ }^{1,2}$, В. Э. Дистановㄹ, И. Н. Гладков ${ }^{1}$ \\ ${ }^{1}$ Институт геологии и минералогии им. В.С. Соболева СО РАН, Новосибирск, Россия \\ ${ }^{2}$ Новосибирский национальный исследовательский государственный университет, \\ Новосибирск, Россия
}

\begin{abstract}
Аннотация: Рассматриваются термохимические мантийные плюмы, имеющие тепловую мощность $1.6 \cdot 10^{10} \mathrm{~B} \mathrm{~T}<N<2.7 \cdot 10^{10} \mathrm{~B}$ и и относительную тепловую мощность $1.15<$ Ка $<1.9$. Такие плюмы мы называем плюмами промежуточной тепловой мощности. Они формируются на границе ядро - мантия под кратонами в отсутствие горизонтальных свободно-конвективных течений в мантии под ними или при наличии слабых горизонтальных мантийных течений. На основе данных лабораторного и теоретического моделирования представлена схема конвективных течений в канале плюма промежуточной тепловой мощности. Плюм поднимается (выплавляется) от границы ядро - мантия до критического уровня хкр, с которого расплав из канала плюма по каналу излияния прорывается на поверхность. Канал излияния образуется под действием силы сверхлитостатического давления на кровлю поднимающегося плюма. При уменьшении высоты массива над

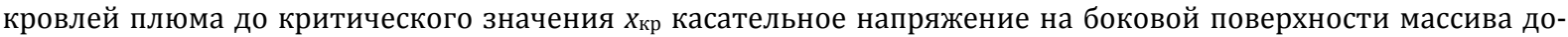

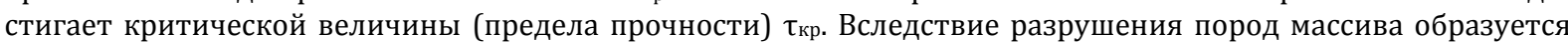
канал излияния высотой хкр, по которому расплав из канала плюма прорывается на поверхность. Представлены оценки высоты канала излияния и времени подъема плюма до критического уровня $x_{к р}$. Определен объем излившегося расплава для его кинематической вязкости v=0.5-2.0 м²/c. С использованием объема излияния получена зависимость глубины $\Delta x$, с которой расплав выносится на поверхность, от диаметра канала плюма для указанных значений $v$. В том случае, когда $\Delta x$ больше 150 км, расплав из канала плюма может транспортировать алмазы на поверхность. Таким образом, плюмы промежуточной тепловой мощности являются алмазоносными. На основе лабораторного моделирования определена структура течения в области сопряжения канала плюма и канала излияния для алмазоносных плюмов. Сделаны фотографии картин течения и измерены профили скорости вдоль линий тока в основном цилиндрическом канале (канале плюма) и в области сопряжения основного канала с каналом истечения. Обнаружена застойная зона, находящаяся в области сопряжения стенки канала плюма и торца, моделирующего кровлю плюма. Течение расплава в канале прорыва проанализировано как турбулентное течение в прямом цилиндрическом канале диаметром $d_{\text {к. }}$ Результаты экспериментального моделирования и теоретического анализа показывают, что сверхлитостатическое давление в канале плюма равно сумме напора, расходуемого на преодоление трения расплава о стенки канала излияния, и напора, расходуемого на увеличение динамического давления в нем. Получено соотношение, связывающее скорость течения расплава в канале излияния и сверхлитостатическое давление у кровли плюма.
\end{abstract}

Ключевые слова: термохимический плюм; тепловая мощность; свободно-конвективные течения; расплав; сверхлитостатическое давление; скорость течения; канал излияния

\section{1. ВВЕДЕНИЕ}

В настоящее время интенсивно развиваются численные модели образования и подъема термохимических плюмов [Kotelkin, Lobkovskii, 2011; Lin, van Keken, 2006; Trubitsyn, Kharybin, 2010; Zhong, 2006; Yang, Fu, 2014; и др.]. В моделях термохимической конвекции под термохимическим плюмом понимается свободно-конвективный восходящий поток (термик) и учитываются изменения плотности, обусловленные вариациями состава. В экспериментах [Whitehead, Luther, 1975; Olson, Singer, 1985] модельный плюм поднимался за счет разности плотностей материала плюма и окружающей жидкости.
Тепловые плюмы представляют собой восходящие свободно-конвективные потоки, создающиеся при локальном нагреве объема вязкой жидкости снизу [Davaille et al., 2011; Kaminski, Jaupart, 2003; Kumagai et al., 2007; Vatteville et al., 2009].

В модели [Kirdyashkin et al., 2004] мантийный термохимический плюм формируется на границе ядро - мантия при наличии теплового потока из внешнего ядра в локализованной области поступления химической добавки, понижающей температуру плавления нижней мантии. Накопление химической добавки вначале происходит вследствие вихревого течения, возникающего во внешнем ядре под действием силы Кориолиса. Затем под дей- 
ствием архимедовой силы легкие компоненты химической добавки втекают в образовавшийся очаг плавления [Kirdyashkin A.G., Kirdyashkin A.A., 2018]. Постоянный приток химической добавки в него обусловливает выплавление (подъем) канала плюма. Отличия вышеуказанной модели термохимического плюма от численных моделей восходящих конвективных течений представлены в статье [Dobretsov et al., 2008].

Источником химической добавки могут быть продукты возможных реакций железосодержащих минералов нижней мантии с водородом и/или метаном, выделяющимся на границе ядро - мантия [Kirdyashkin et al., 2004]. На наличие химической добавки может указывать то обстоятельство, что изверженные породы плюмов промежуточной мощности, ответственных за образование кимберлитовых трубок (трубок взрыва), содержат большое количество $\mathrm{CO}_{2}$ (до 12.8-20.5 \%) [Dawson, 1980]. Взрывообразный характер извержения таких плюмов указывает на большое количество $\mathrm{CO}_{2}$ при прорыве плюма на поверхность [Dawson, 1980; Fedortchouk et al., 2010].

Рассматриваются плюмы с тепловой мощностью $N=(1.6-2.7) \cdot 10^{10}$ Вт. Она больше, чем предельная тепловая мощность, эти плюмы способны прорываться на поверхность, но при указанных значениях $N$ не происходит формирования грибообразной головы плюма в литосфере [Kirdyashkin A.A., Kirdyashkin A.G., 2016]. Такие плюмы будем называть плюмами промежуточной тепловой мощности. Плюмы с тепловой мощностью $N<1.6 \cdot 10^{10}$ Вт не достигают поверхности и называются плюмами малой тепловой мощности [Kirdyashkin A.A., Kirdyashkin A.G., 2016]. Статья подготовлена по материалам нашего доклада на дискуссионном столе «Петрология мантии и петрологические индикаторы мантийно-корового взаимодействия: математическое моделирование и геологические сценарии» в рамках IV международной научной конференции «Корреляция алтаид и уралид» (2-6 апреля 2018 г., г. Новосибирск) и представляет собой обзор и анализ наших предыдущих исследований плюмов промежуточной мощности. В задачу нашего исследования входит: (1) определение тепловой и гидродинамической структуры термохимических плюмов промежуточной мощности, оценка их основных параметров и геодинамических условий излияния расплава, образованного этими плюмами; (2) определение гидродинамической структуры течения в канале термохимического плюма у его кровли и в области сопряжения канала плюма с каналом излияния, по которому магматический расплав из канала плюма прорывается на поверхность.

В статье на основе данных лабораторного и теоретического моделирования предложена схема ка- нала плюма, поднимающегося (выплавляющегося) от границы ядро - мантия, и свободно-конвективных течений в расплаве канала. Рассмотрена модель двухстадийного излияния расплава из канала плюма на поверхность, и представлены выражения для сверхлитостатического давления, критического касательного напряжения на боковой поверхности массива над кровлей плюма и высоты канала излияния. С использованием указанной модели получены зависимости объема излившегося расплава и глубины, с которой он выносится на поверхность, от диаметра плюма. На основании зависимости глубины выноса расплава от диаметра плюма выделены плюмы, расплав из канала которых может доставлять алмазы на поверхность, и плюмы, расплав которых не транспортирует алмазы на поверхность. Далее представлены результаты экспериментального моделирования течения расплава в области сопряжения канала алмазоносного плюма и канала излияния. В заключение получено выражение для перепада давления в канале излияния и показана его зависимость от скорости течения расплава.

\section{2. ТЕПЛОВАЯ И ГИДРОДИНАМИЧЕСКАЯ СТРУКТУРА КАНАЛА ПЛЮМА}

Рассматривается мантийный плюм, поднимающийся (выплавляющийся) от границы ядро - мантия. В статьях [Gladkov et al., 2012; Kirdyashkin et al., 2012] было показано, что происходит смена режимов выплавления канала плюма: (1) плюм зарождается на границе ядро - мантия и поднимается (выплавляется) до высоты $x_{\text {тх }}$ как термохимический, в котором определяющим является массообмен; (2) при $X_{\mathrm{Tx}}<x<H$, где $H=2880$ км - расстояние от границы ядро - мантия до поверхности, определяющим является теплообмен, присутствие химической добавки понижает температуру плавления мантии, но уже не лимитирует процессы теплообмена в плюме. Соотношение для определения высоты $x_{\text {тх }}$ представлено в цитированных работах, величина $x_{\mathrm{Tx}}=200$ км [Kirdyashkin A.A., Kirdyashkin A.G., 2016]. Поскольку слой мантии толщиной $x_{\mathrm{Tx}}$, в котором плюм поднимается как термохимический, составляет 7 \% от толщины всей мантии, возможно лабораторное моделирование мантийного плюма как теплового, создающегося при плавлении над локальным источником тепла [Gladkov et al., 2012; Kirdyashkin et al., 2012].

Будем использовать относительную тепловую мощность плюма Ка $=N / N_{1}$, где $N$ - тепловая мощность, передаваемая от подошвы плюма в его канал, $N_{1}=0.5 \pi \lambda_{\text {ом }} \Delta T H-$ тепловая мощность, передаваемая каналом плюма окружающему массиву ман- 
тии в режиме стационарной теплопроводности, $\lambda_{\text {ом }}$ - коэффициент теплопроводности окружающей мантии, $\Delta T=T_{\text {пл }}-T_{0}, T_{\text {пл }}$ - температура границы канала плюма, $T_{0}$ - температура окружающей мантии на удалении от канала, $H$ - высота канала плюма. Критерий Ка позволяет оценить увеличение интенсивности теплоотвода от канала плюма в условиях нестационарного кондуктивного теплообмена по сравнению со стационарным. Для стационарного кондуктивного теплообмена между каналом и окружающим массивом Ка=1 $\left(N=N_{1}\right)$.

Для плюма, поднимающегося (выплавляющегося) от границы ядро - мантия к поверхности Земли, $H=2880$ км и для средних значений для всей мантии $\lambda_{\text {ом }}=7 \mathrm{BT} / \mathrm{M}^{\circ}{ }^{\circ} \mathrm{C}$ и $\Delta T=440{ }^{\circ} \mathrm{C}$ [Dobretsov et al., 2001 ; Kirdyashkin et al., 2009] получаем $N_{1} \approx 1.4 \cdot 10^{10}$ Вт. Экспериментальные исследования формы канала плюма, выплавляющегося в твердом массиве, позволяют определить относительную тепловую мощность плюма $\mathrm{Ka}_{1}$, при которой он прорывается на поверхность массива: Ка $1=1.15$. При значениях $\mathrm{Ka}_{2}>1.6-1.9$ плюм достигает поверхности твердого массива и происходит плавление вдоль нее с формированием грибообразной головы плюма [Gladkov et al., 2012; Kirdyashkin et al., 2012].

Рассмотрим плюмы, прорывающиеся на поверхность без образования грибообразной головы и имеющие тепловую мощность $N=(1.6-2.7) \cdot 10^{10}$ Вт и относительную тепловую мощность Ка=N/N $N_{1}=1.15-$ 1.90 [Kirdyashkin et al., 2016]. Такие плюмы, имеющие тепловую мощность, бо́льшую, чем $N_{1}$, могут существовать под кратонами, где удельный тепловой поток на границе ядро - мантия $q_{\text {ям достаточно }}$ низкий. Используя данные по мантийной составляющей теплового потока для тектонически стабильных континентальных регионов [Jaupart, Mareschal, 2007, 2014; u дp.], можно оценить тепловой поток на границе ядро - мантия (исходя из отношения квадратов радиусов Земли и ядра) как $q_{\text {ям }}=0.027-0.061$ Вт/м². Низкие тепловые потоки указывают на низкую интенсивность свободноконвективных течений в мантии в таких регионах, т.е. в мантии под кратонами можно ожидать очень слабые свободно-конвективные течения и их влиянием в этих областях можно пренебречь. При таких условиях на поверхность Земли могут прорываться плюмы, имеющие вышеуказанную тепловую мощность $N>N_{1}$. В океанических областях существует интенсивный теплоотвод от каналов плюмов в окружающую мантию вследствие горизонтальных мантийных свободно-конвективных течений. Здесь на поверхность могут прорываться только плюмы большой тепловой мощности, такие как Гавайский, тепловая мощность которого $N=3 \cdot 10^{11}$ Вт и $\mathrm{Ka}=N / N_{1}=21.4$ [Kirdyashkin A.A., Kirdyashkin A.G., 2016].
Схема канала плюма и свободно-конвективные течения в расплаве канала показаны на рис. 1 на основе данных экспериментального моделирования. В вертикальном сечении канал плюма представляет собой систему конвективных ячеек. В областях сужения на границах ячеек восходящий конвективный поток переходит на противоположную сторону канала. Пограничный слой нисходящего конвективного течения расположен по образующей поверхности канала. Граница канала изменяется во времени. Вдоль области восходящего потока происходит плавление, вдоль нисходящего потока - кристаллизация на границе и в областях сужения канала (при уменьшении его диаметра). Поверхность канала плюма можно рассматривать как «бегущую волну»; между границей канала и окружающим массивом происходит нестационарный кондуктивный теплообмен [Gladkov et al., 2012; Kirdyashkin et al., 2012]. Диаметр канала плюма $d=2 R$ ( $R$ - радиус канала) соизмерим с диаметром его подошвы. Диаметр сужения канала $d_{\mathrm{c}}=2 R_{\mathrm{c}}=0.5 d$, где $R_{\mathrm{c}}$ - радиус сужения.

Согласно нашим модельным экспериментам [Kirdyashkin et al., 2005; Dobretsov et al., 2008], при выплавлении (подъеме) термохимического плюма объем расплавленного мантийного вещества становится больше объема твердого вещества проплавляемого массива мантии, поэтому избыточный объем расплава вытекает у его подошвы. Таким образом, за время выплавления (подъема) плюма $t_{1}$ до

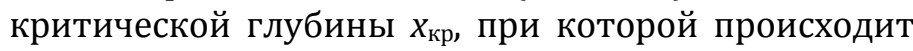
прорыв расплава, образованного плюмом, на поверхность, в окрестности подошвы плюма скапливается расплав (рис. 1). Удельный массовый поток расплава, накапливающегося у подошвы плюма $\Delta G$, определяется из соотношения [Dobretsov et al., 2008]:

$$
\Delta G=N \beta / C
$$

где $\beta$ - коэффициент теплового объемного расширения мантийного вещества, $C$ - его теплоемкость. Масса расплава, скапливающегося у подошвы плюма за время $t_{1}, G_{\mathrm{p}}=\Delta G t_{1}$. Тепловую мощность на подошве плюма можно определить из соотношения (1), если из геологических данных об объеме излившихся магм и времени излияния известен удельный массовый поток $\Delta G$. Также тепловую мощность на подошве плюма можно определить, используя соотношение [Kirdyashkin et al., 2004]:

$$
N=0.045 \pi \lambda d^{2} \Delta T^{4 / 3}(\beta g / a v)^{1 / 3},
$$

где $g$ - гравитационное ускорение, $a$ - коэффициент температуропроводности, $\lambda$ - коэффициент теплопроводности, $v$ - кинематическая вязкость расплава в канале плюма. 


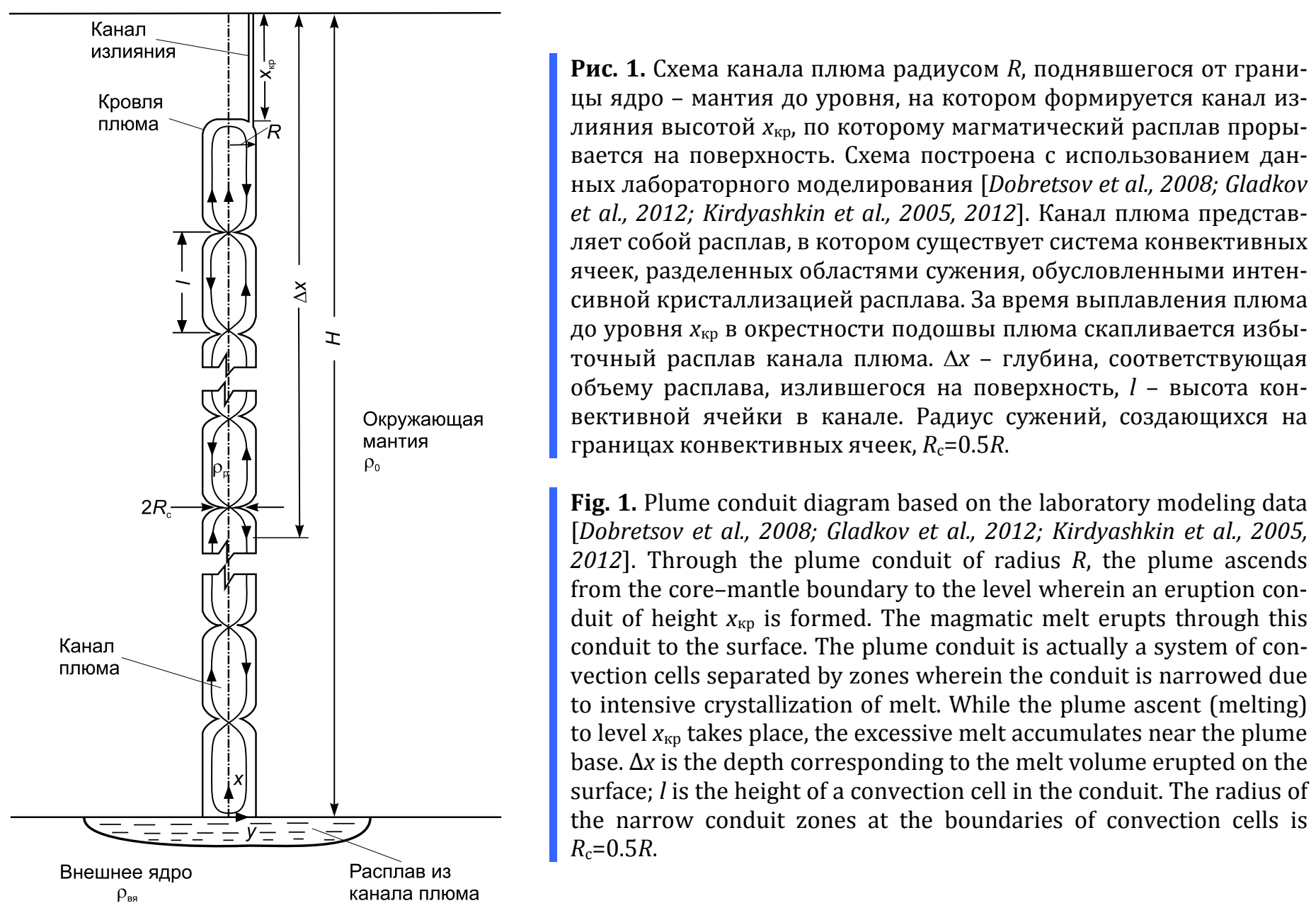

\section{3. МОДЕЛЬ ИЗЛИЯНИЯ РАСПЛАВА ИЗ КАНАЛА ПЛЮМА ПРОМЕЖУТОЧНОЙ МОЩНОСТИ И ФОРМИРОВАНИЯ КАНАЛА ИЗЛИЯНИЯ}

Результаты лабораторного и теоретического моделирования процесса излияния расплава из канала термохимического плюма представлены в работах [Kirdyashkin et al., 2005; Dobretsov et al., 2008]. Из лабораторного моделирования термохимических плюмов следует, что излияние магматического расплава из канала термохимического плюма осуществляется в две стадии. На первой стадии излияния расплав из канала термохимического плюма прорывается на поверхность (раздел 4). Прорыв расплава происходит под воздействием силы сверхлитостатического давления на кровлю плюма.

Так как плотность расплава меньше плотности окружающей мантии, давление в расплаве под кровлей плюма превышает литостатическое давление пород над кровлей плюма на величину $\Delta P$, согласно соотношению [Kirdyashkin et al., 2005], которое с учетом диаметра сужений канала плюма имеет вид:

$$
\Delta P=\rho_{0} \beta g\left(H-X_{\text {кр }}\right)\left(T_{\mathrm{p}}-T_{0}\right)\left(d_{\mathrm{c}} / d\right)^{2},
$$

где $\rho_{0}$ - плотность окружающей мантии, $T_{\mathrm{p}}$ - температура расплава в канале плюма, $T_{0}$ - температура окружающей мантии. Для значений параметров $\rho_{0}=4500$ кг $/ \mathrm{M}^{3}, \beta=(1-3) \cdot 10^{-5}{ }^{\circ} \mathrm{C}-1, g=9.8 \mathrm{~m} / \mathrm{c}^{2}, H=2.88 \cdot 10^{6} \mathrm{M}$, $x_{\text {кр }}=12 \cdot 10^{3}$ м (см. ниже), $T_{\mathrm{p}}-T_{0}=440^{\circ} \mathrm{C}$ и $\left(d_{\mathrm{c}} / d\right)^{2}=0.25$ получаем $\Delta P=(1.4-4.2) \cdot 10^{8} \mathrm{H} / \mathrm{m}^{2}\left(10^{8} \mathrm{H} / \mathrm{m}^{2}=1\right.$ кбар).

Сила давления $F$ на кровлю поднимающегося плюма

$$
F=\Delta P\left(\pi d^{2} / 4\right)
$$

вызывает движение в массиве коры, находящемся над кровлей плюма. Касательное напряжение в массиве над кровлей плюма возрастает с уменьшением высоты массива. Наконец, при достижении критического

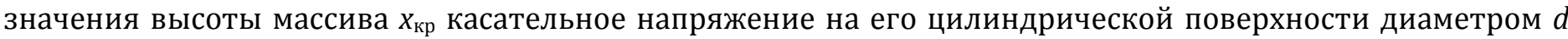




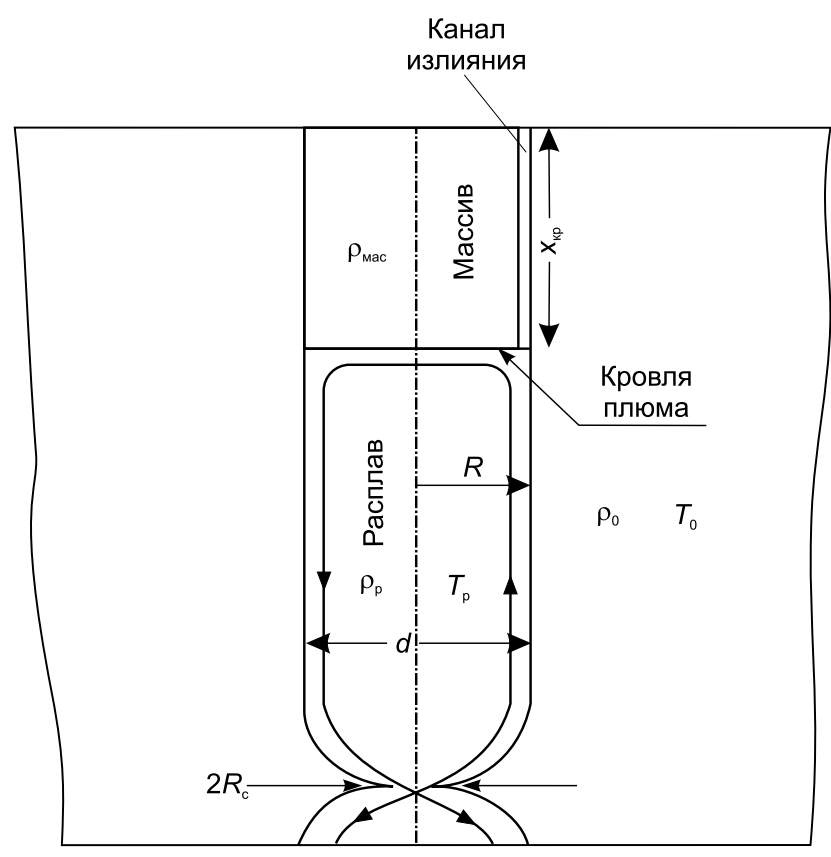

Рис. 2. Кровля плюма диаметром $d$ и цилиндрический массив над ней при подходе плюма к дневной поверхности. На боковой поверхности массива под действием си-

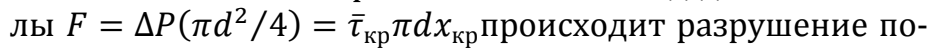
род и образуется канал излияния высотой $X_{\text {кр. }}$.

Fig. 2. The plume roof (diameter $d$ ) and the cylindrical block above it when the plume approaches the Earth's surface. Rock fails near the sidewall of the block under the effect of the force $F=\Delta P\left(\pi d^{2} / 4\right)=\bar{\tau}_{\mathrm{\kappa p}} \pi d x_{\mathrm{\kappa p}}$. Hence, the eruption conduit of height $x_{\mathrm{\kappa p}}$ forms.

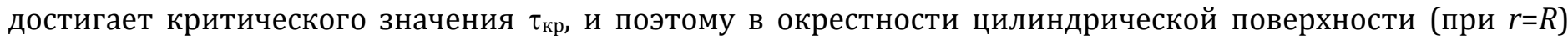
наиболее вероятно разрушение пород массива и формирование канала, по которому магматический расплав из канала плюма изливается на поверхность, т.е. канала излияния. Движение в массиве над кровлей плюма диаметром $d$ будем рассматривать в первом приближении как вязкое течение в цилиндрическом канале диаметром $d$ [Kirdyashkin et al., 2005; Dobretsov et al., 2008]. Наибольшее касательное напряжение достигается на боковой поверхности массива над кровлей плюма (при $r=R$ ) и равно нулю на его оси (при $r=0$ ), поэтому наиболее вероятно разрушение пород массива в окрестности цилиндрической поверхности радиусом $R=d / 2$ и формирование канала излияния.

Критическое касательное напряжение на боковой поверхности цилиндрического массива над кровлей

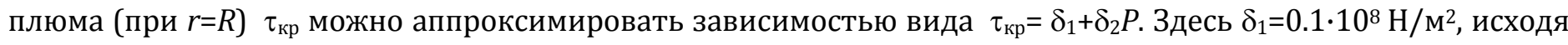
из данных по временному сопротивлению на срез (скалывание) при давлении 1 атм для различных магматических и осадочных пород [Azhgirey, 1956], и $\delta_{2}=0.3$, исходя из экспериментальных данных П.В. Бриджмена по сопротивлению сдвигу под всесторонним давлением для ряда минералов и магматических пород [Kirdyashkin et al., 2005; Dobretsov et al., 2008]. Давление $P$ есть сумма литостатического давления $\rho_{\text {кор }} g x_{\text {кр }}$ и сверхлитостатического давления $\Delta P$, определяемого соотношением (3), $P=\rho_{\text {мас }} g x_{\mathrm{kp}}+\rho_{0} \beta g H\left(T_{\mathrm{p}}-T_{0}\right)\left(d_{c} / d\right)^{2}$, где $\rho_{\text {мас }}$ средняя плотность по высоте массива над кровлей плюма, $x_{\text {кр }}$ критическая высота массива над кровлей плюма (рис. 2). Тогда имеем

$$
\tau_{\text {кр }}=\delta_{1}+\delta_{2}\left[\rho_{\text {мас }} g x_{\text {кр }}+\rho_{0} \beta g H\left(T_{\mathrm{p}}-T_{0}\right)\left(d_{\mathrm{c}} / d\right)^{2}\right] .
$$

Предел прочности, усредненный по высоте массива $x_{\text {кр }}, \overline{\tau_{\text {кp }}}=\left(1 / x_{\text {кр }}\right) \int_{0}^{x_{\text {кр }}} \tau_{\text {кр }} d x$, и тогда, учитывая равенство (5), в результате интегрирования получаем

$$
\overline{\tau_{\text {кр }}}=\delta_{1}+0.5 \delta_{2} \rho_{\text {мас }} g x_{\text {кр }}+0.5 \rho_{0} \beta g H\left(T_{\mathrm{p}}-T_{0}\right)\left(d_{\mathrm{c}} / d\right)^{2} .
$$

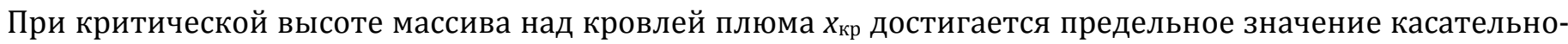

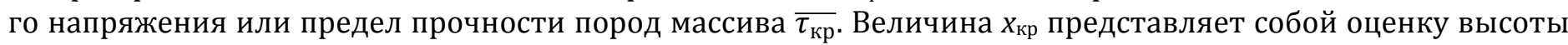
канала излияния или, другими словами, указывает на глубину, с которой магма из канала плюма при его подъеме к дневной поверхности отводится по каналу излияния в массиве над кровлей и изливается на поверхность.

Определим критическую высоту массива, или, другими словами, высоту канала излияния [Kirdyashkin et $a l ., 2005]$. Касательное напряжение на боковой поверхности массива над кровлей плюма при $r=R$ (рис. 2) достигает критического значения $\overline{\tau_{\text {кр}}}$, когда суммарное давление на кровлю плюма равно силе трения на цилиндрической поверхности радиусом $R$. 


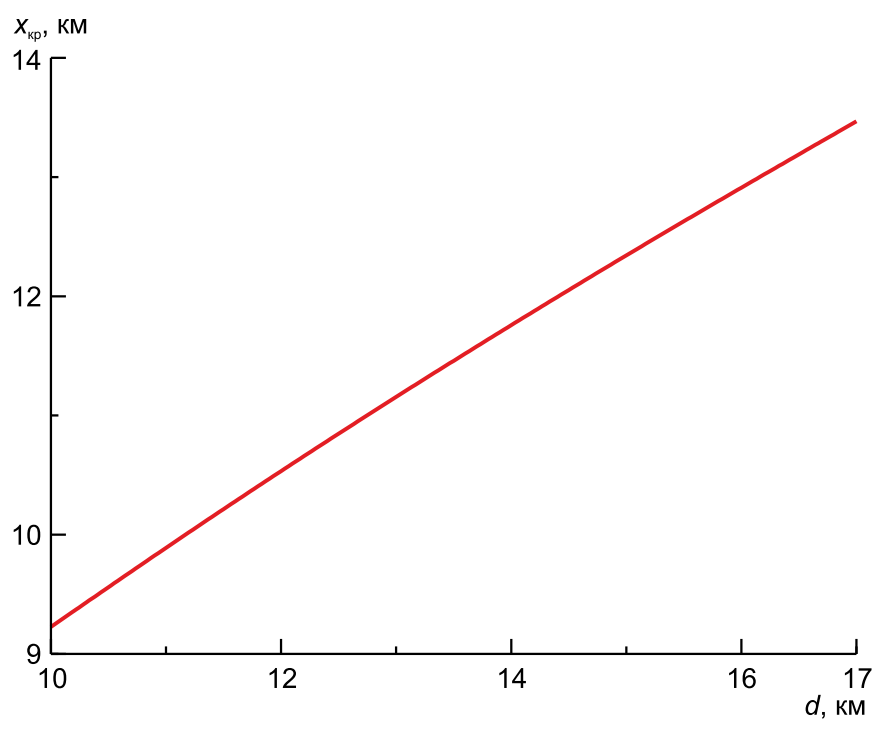

Рис. 3. Зависимость критической высоты массива над кровлей плюма (высоты канала излияния) от диаметра канала плюма $d$.

Fig. 3. Critical height of the massif above the plume roof (i.e. height of the plume conduit) vs. plume tail diameter $d$.

Суммарную силу давления на кровлю плюма определяем из соотношений (3) и (4), учитывая при этом, что $H>>X_{\text {кр }}$

$$
F=(\pi / 4) d_{\mathrm{c}}^{2} \rho_{0} \beta g H\left(T_{\mathrm{p}}-T_{0}\right) .
$$

Среднее значение $\overline{\tau_{\text {кр }}}$ на боковой поверхности цилиндрического массива над кровлей плюма при $r=R$ равно $\overline{\tau_{\text {кр }}}=F / \pi d x_{\text {кр }}$ и, согласно соотношению (7),

$$
\overline{\tau_{\mathrm{\kappa p}}}=\rho_{0} \beta g H\left(T_{\mathrm{p}}-T_{0}\right) d_{\mathrm{c}}^{2} / 4 d x_{\mathrm{\kappa p}} .
$$

Приравнивая правые части соотношений (6) и (8) и решая получившееся уравнение, находим $X_{\kappa р}$ :

$$
x_{\text {кр }}=\frac{-\left[8 \delta_{1}+\delta_{2} \rho_{0} \beta g H\left(T_{\mathrm{p}}-T_{0}\right)\right]+\left[\left(8 \delta_{1}+\delta_{2} \rho_{0} \beta g H\left(T_{\mathrm{p}}-T_{0}\right)\right)^{2}+16 \delta_{2} \rho_{\text {мас }} \rho_{0} g^{2} \beta H\left(T_{\mathrm{p}}-T_{0}\right) d_{c}\right]^{1 / 2}}{8 \delta_{2} \rho_{\text {мас }} g} .
$$

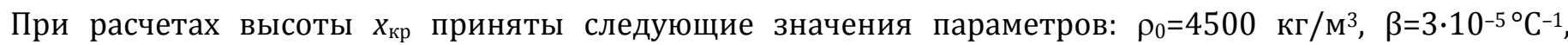
$g=9.8 \mathrm{M} / \mathrm{c}^{2}, \quad H=2.88 \cdot 10^{6} \mathrm{M}, \quad \rho_{\text {мас }}=3000$ кг $/ \mathrm{M}^{3}, \quad T_{\mathrm{p}}-T_{0}=440{ }^{\circ} \mathrm{C}, d_{\mathrm{c}} / d=0.5$. Как указано выше, принимаем

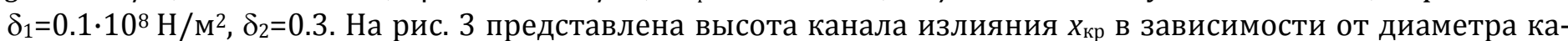

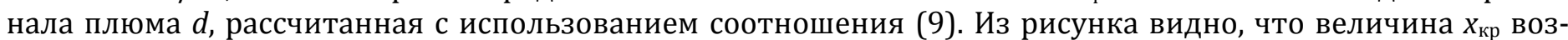

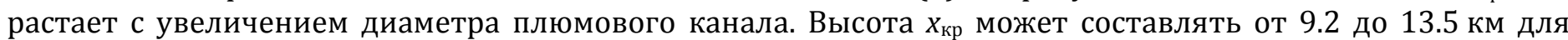
диаметра $d$, изменяющегося от 10 до 17 км. В случае плюмов, имеющих Ка > 1.9, после прорыва расплава на поверхность происходит плавление окружающего корового массива и образуется грибообразная голова плюма [Kirdyashkin A.A., Kirdyashkin A.G., 2016]. Для таких плюмов критическая высота массива над кровлей

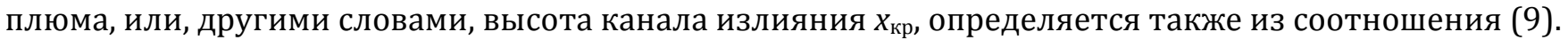

\section{4. ОБЪЕМ ИЗЛИЯНИЯ ТЕРМОХИМИЧЕСКИХ ПЛЮМОВ ПРОМЕЖУТОЧНОЙ МОЩНОСТИ И ГЛУБИНА, С КОТОРОЙ РАСПЛАВ ВЫНОСИТСЯ ИЗ КАНАЛА ПЛЮМА НА ПОВЕРХНОСТЬ}

Как показывает лабораторное моделирование прорыва плюма на поверхность твердого массива, на первой стадии излияния расплава из канала термохимического плюма на поверхность объем расплава, изливающегося из верхней части плюма, равен объему расплава, накопившегося у подошвы плюма. При прорыве плюма на поверхность расплав, скопившийся у подошвы плюма, поднимается в его канал. Объем излившегося расплава на первой стадии [Dobretsov et al., 2008]

$$
V_{1}=N \beta t_{1} / \rho_{\text {и }} C
$$

где тепловая мощность плюма $N$ определяется из соотношения (2), $\rho_{и}$ - плотность излившихся пород. 
Сразу же после первой стадии излияния от подошвы плюма в его канал поднимается вещество жидкого внешнего ядра, и из верхней части плюма изливается расплав, выдавленный из канала плюма веществом внешнего ядра, поднявшимся в канал [Kirdyashkin et al., 2005; Dobretsov et al., 2008]. Подъем вещества внешнего ядра можно объяснить следующим образом. Прорыв расплава происходит под воздействием силы сверхлитостатического давления на кровлю плюма. После излияния расплава на поверхность гидростатическое давление столба расплава на подошве плюма, расположенной на границе ядро - мантия, становится меньше, чем литостатическое давление на границе ядро мантия, поскольку расплав плюма имеет бо́льшую температуру и он легче, чем вещество окружающей мантии. Под действием разности давления столба расплава и литостатического давления на границе ядро - мантия происходит подъем вещества внешнего ядра в канале плюма. Можно оценить высоту

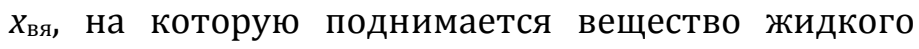
внешнего ядра в канале плюма после прорыва плюма на поверхность [Kirdyashkin et al., 2005; Dobretsov et al., 2008]. Для упрощения рассматривается плотность окружающей мантии $\rho_{0}$, усредненная по ее толщине $H$. Пусть $\rho_{p}$ - средняя плотность расплава

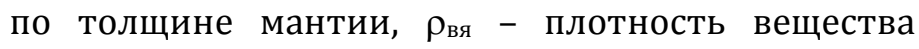
внешнего ядра. После излияния плюма литостатическое давление на границе ядро - мантия $\rho_{0} g H$ уравновешивается давлением столба расплава вы-

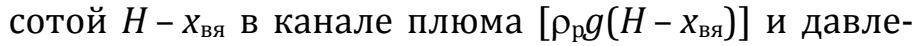
нием столба материала внешнего ядра высотой $x_{\text {вя, }}$ поднявшегося в канал плюма $\left(\rho_{\text {вя }} g x_{\text {вя }}\right)$ :

$$
\rho_{0} g H=\rho g\left(H-X_{\text {вя }}\right)+\rho_{\text {вя }} g X_{\text {вя }}
$$

Из этого соотношения можно определить высоту, на которую поднимается в канал плюма вещество внешнего ядра:

$$
x_{\text {вя }}=H\left(\rho_{0}-\rho_{\mathrm{p}}\right) /\left(\rho_{\text {вя }}-\rho\right) \text {. }
$$

Вследствие теплового расширения $\rho_{0}-\rho=\rho_{0} \beta\left(T_{\mathrm{p}}-T_{0}\right)$, и тогда

$$
x_{\text {вя }}=\frac{\rho_{0} \beta H\left(T_{\mathrm{p}}-T_{0}\right)}{\rho_{\text {вя }}-\rho_{0}\left[1-\beta\left(T_{\mathrm{p}}-T_{0}\right)\right]} .
$$

Для $H=2.88 \cdot 10^{6} \mathrm{~m}, \rho_{0}=4500$ кг $/ \mathrm{M}^{3}, \beta=3 \cdot 10^{-5^{\circ}} \mathrm{C}^{-1}$, $T_{\mathrm{p}}-T_{0}=440{ }^{\circ} \mathrm{C}$ и $\rho_{\text {вя }}=10^{4} \mathrm{\kappa г} / \mathrm{M}^{3}$ из (13) получается высота подъема вещества внешнего ядра $x_{\text {вя }}=31$ км.

Объем излившегося расплава на второй стадии излияния:

$$
V_{2}=\pi R^{2} X_{\text {вя. }}
$$

Общий объем расплава, излившегося на поверхность, $V=V_{1}+V_{2}$, учитывая равенства (10) и (14),

$$
V=N \beta t_{1} / \rho_{\text {и }} C+\pi R^{2} X_{\text {вя. }}
$$

Время подъема плюма до уровня $x_{\text {кр }}$ с которого плюм прорывается на поверхность, определяется с использованием соотношения [Kirdyashkin et al., 2004]:

$$
t_{1}=\frac{-\rho_{0} d^{2}\left(B+C \Delta T_{0}\right)}{2 \lambda \Delta T_{0}} \ln \left(1-\frac{11.1 \Delta T_{0}\left(H-x_{\mathrm{Kp}}\right)}{d^{2} \Delta T_{\mathrm{S}}^{4 / 3}(\beta g / a v)^{1 / 3}}\right),
$$

где $B$ - теплота плавления вещества в канале плюма, $\lambda$ - теплопроводность расплава в канале, $\Delta T_{0}=T_{\mathrm{p}}-T_{0}$, $\Delta T_{\mathrm{s}}=\left(T_{1}-T_{\text {пх }}\right) / 1.57$ - перепад температуры в пограничном слое на подошве плюма [Kirdyashkin A.A., Kirdyashkin A.G. 2016], a - температуропроводность, $v$ - кинематическая вязкость расплава.

Результаты расчетов, представленные ниже в этом разделе, получены для следующих значений

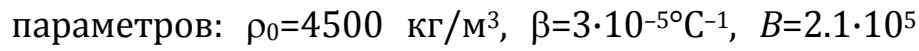
Дж/кг, $C=1.2 \cdot 10^{3}$ Дж/кг ${ }^{\circ} \mathrm{C}, \lambda=7$ Вт $/{ }^{\circ} \cdot{ }^{\circ} \mathrm{C}, a=1.3 \cdot 10^{-6}$ $\mathrm{M}^{2} / \mathrm{c}, \Delta T_{0}=T_{\mathrm{p}}-T_{0}=440^{\circ} \mathrm{C}, \Delta T_{\mathrm{s}}=10^{\circ} \mathrm{C}$. В статье [Kirdyashkin et al., 2009] на основе анализа теплообмена между каналом термохимического плюма и горизонтальными нижнемантийными свободно-конвективными течениями получены оценки кинематической вязкости расплава в канале плюма. Учитывая эти оценки, принимаем кинематическую вязкость расплава в канале плюма $v$ равной $0.5,1.0$ и $2.0 \mathrm{~m}^{2} / \mathrm{c}$. Расстояние от границы ядро - мантия до поверхности $H=2.88 \cdot 10^{6} \mathrm{M}$, диаметр сужения канала плюма $d_{c}=0.5 d$.

Для определения объема излившегося магматического расплава необходимо знать время $t_{1}$ от зарождения плюма на границе ядро - мантия до прорыва расплава на поверхность по каналу изли-

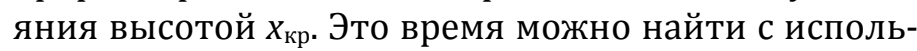
зованием соотношения (16). Время подъема плюма $t_{1}$ в зависимости от диаметра канала плюма для различных кинематических вязкостей расплава в канале представлено на рис. 4. Пунктирными линиями показаны минимальные значения диаметра $d_{\min }$, при которых плюмы промежуточной мощности $(1.15<\mathrm{Ka}<1.9)$ еще достигают поверхности. Для диаметров, меньших $d_{\min }$, время подъема $t_{1}$ стремится к бесконечности, т.е. плюмы с такими диаметрами не прорываются на поверхность. Для $v=0.5 \mathrm{~m}^{2} / \mathrm{c}$ диаметр $d_{\min }=9.2$ км, для $v=1 \mathrm{~m}^{2} / \mathrm{c}$ $d_{\min }=10.4$ км и для $v=2.0 \quad \mathrm{M}^{2} / \mathrm{c} \quad d_{\min }=11.7 \quad$ км. С увеличением диаметра канала плюма и уменьшением вязкости расплава время подъема $t_{1}$ уменьшается.

Высота столба расплава, соответствующая объему излившегося расплава $V$, или, другими словами, глубина $\Delta x$, с которой расплав был вынесен из канала плюма на поверхность (см. рис. 1), определяется выражением: 


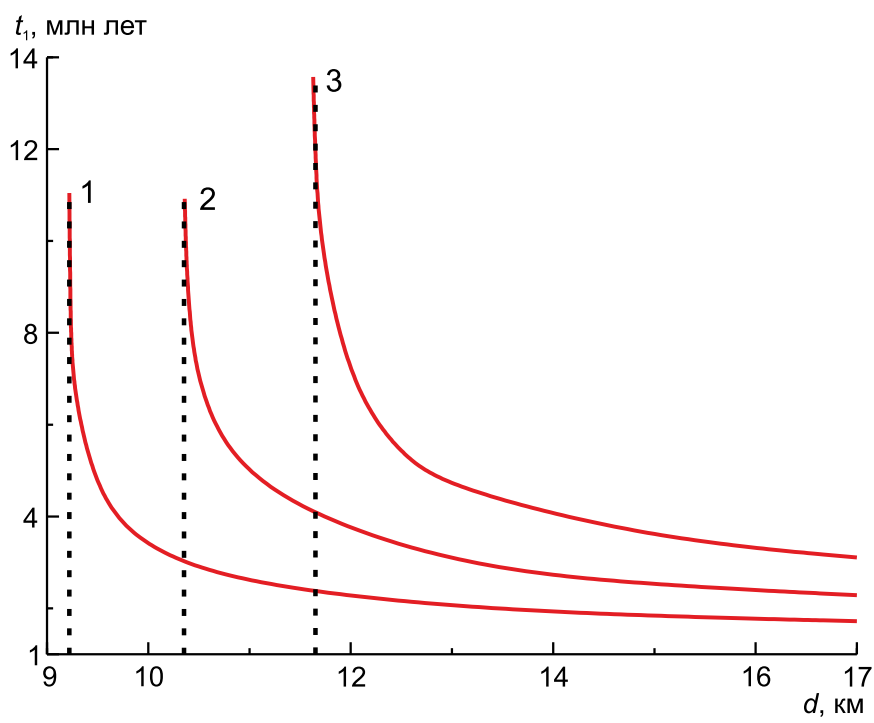

Рис. 4. Время подъема плюма $\mathrm{t}_{1}$ до уровня $x_{\text {кр }}$ в зависимости от диаметра канала плюма $d$ для различных значений кинематической вязкости расплава $v$ в нем. $1-v=0.5 \mathrm{~m}^{2} / \mathrm{c} ; 2-v=1 \mathrm{~m}^{2} / \mathrm{c} ; 3-\mathrm{v}=2 \mathrm{M}^{2} / \mathrm{c}$.

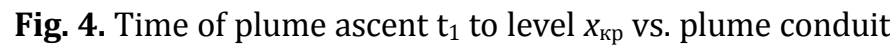
diameter $d$ for different values of kinematic viscosity $v$. $1-\mathrm{v}=0.5 \mathrm{~m}^{2} / \mathrm{s} ; 2-\mathrm{v}=1 \mathrm{~m}^{2} / \mathrm{s} ; 3-\mathrm{v}=2 \mathrm{~m}^{2} / \mathrm{s}$.

$$
\Delta x=4 V / \pi d^{2},
$$

где $d$ - диаметр канала плюма.

Объем расплава, изливающегося при прорыве плюма на поверхность $(V)$, вычислен на основании соотношений (2), (14) и (15). В вычислениях объема излияний приняты значения: $\rho_{\text {и }}=3000$ кг/ ${ }^{3}$ и $x_{\text {вя }}=31$ км. Зависимость объема излияний от диаметра канала плюма представлена на рис. 5 для различных значений кинематической вязкости расплава в канале. Точки пересечения прямой с кривыми 1-3 (рис. 5) отвечают граничным значениям диаметра канала плюма $d_{\text {гр }}$, при которых достигается граничное значение относительной тепловой мощности Ка=1.9. Эта тепловая мощность соответствует переходу от плюмов, прорвавшихся на поверхность, но не образующих грибообразную голову, к плюмам с грибообразной головой [Kirdyashkin A.A., Kirdyashkin A.G., 2016]. Граничные значения диаметра канала плюма $d_{\text {гр }}$ равны соответственно 12.6 км, 14.2 км и 16.1 км для $v=0.5 \mathrm{~m}^{2} / \mathrm{c}$, 1 м²/с и 2 м²/с. Как видно из рис. 5, диаметр плюмов промежуточной тепловой мощности, прорывающихся на поверхность, изменяется от минимальных значений $d_{\min }$, приведенных на рис. 4 , до

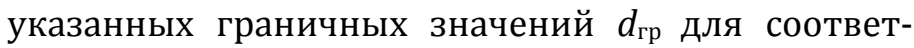
ствующей вязкости расплава. Так, для $v=1 \mathrm{M}^{2} / \mathrm{c}$ диаметр канала плюма $d=10.4-14.2$ км (рис. 5, кривая 2). Как следует из рис. 5, для плюмов, прорыва- ющихся на поверхность, объем излияний может составлять от $1.3 \cdot 10^{4}$ до $5 \cdot 10^{4} \mathrm{KM}^{3}$.

Зная объем излияний $V$, с помощью соотношения (17) можно определить глубину $\Delta x$, с которой расплав был вынесен из канала плюма на поверхность. На рис. 6 показана зависимость глубины $\Delta x$ от диаметра канала плюма для различных значений кинематической вязкости расплава. Глубина $\Delta x$ уменьшается от 500 до 125 км с увеличением диаметра плюма от $d=d_{\min }$ до $d=17$ км.

Кимберлиты, наряду с ареалами платобазальтов, представляют собой важнейшие проявления мантийных плюмов на поверхности [Dobretsov et al., 2001; Chalapathi Rao, Lehmann, 2011]. Геодинамические модели указывают на то, что излияние кимберлитовых магм, выносящих алмазы на поверхность, связано с мантийными плюмами, поднимающимися от границы ядро - мантия [Torsvik et al., 2010]. Глубина $\Delta x$, начиная с которой алмаз устойчив, равна 150 км [Kennedy C.S., Kennedy G.C., 1976]. Прямая $\Delta x=150$ км проведена на рис. 6. В том случае, когда $\Delta x>150$ км, расплав из канала плюма может доставлять алмазы на поверхность и участки кривых 1-3, лежащие выше границы 150 км, относятся к плюмам промежуточной тепловой мощности, выносящим алмазы на поверхность. Расплав плюма, вынесенный с глубины $\Delta x<150$ км, не будет

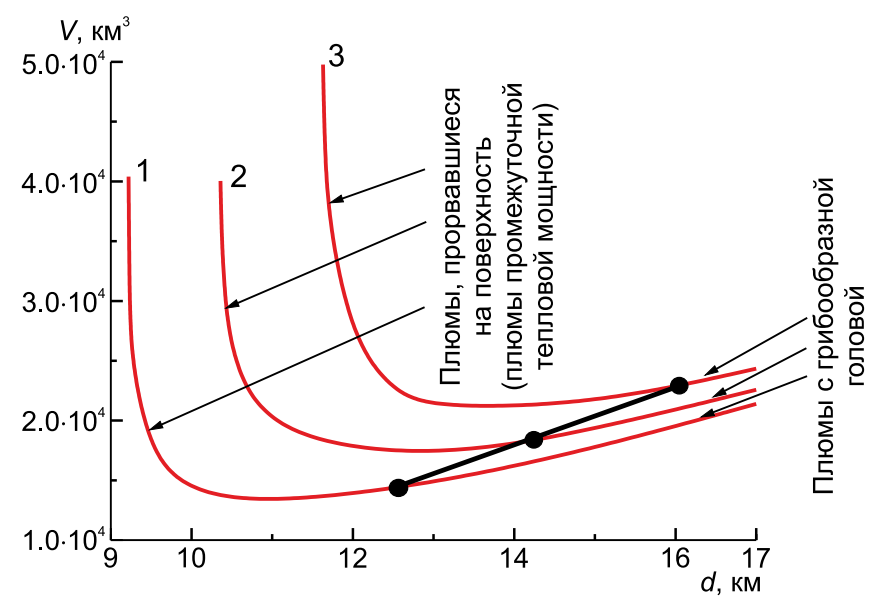

Рис. 5. Зависимость объема излившегося расплава от диаметра $d$ для различных значений v. Прямая разграничивает объемы излияний для плюмов, прорвавшихся на поверхность (плюмов промежуточной тепловой мощности), и для плюмов с грибообразной головой. $1-v=0.5 \mathrm{~m}^{2} / \mathrm{c} ; 2-v=1 \mathrm{~m}^{2} / \mathrm{c} ; 3-v=2 \mathrm{~m}^{2} / \mathrm{c}$.

Fig. 5. Erupted melt volume vs. diameter $d$ for different values of $v$. Straight line separates eruption volumes for plumes that reached the surface (plumes with the intermediate thermal power) and plumes with mushroomshaped heads. $1-v=0.5 \mathrm{~m}^{2} / \mathrm{s} ; 2-\mathrm{v}=1 \mathrm{~m}^{2} / \mathrm{s} ; 3-\mathrm{v}=2 \mathrm{~m}^{2} / \mathrm{s}$. 


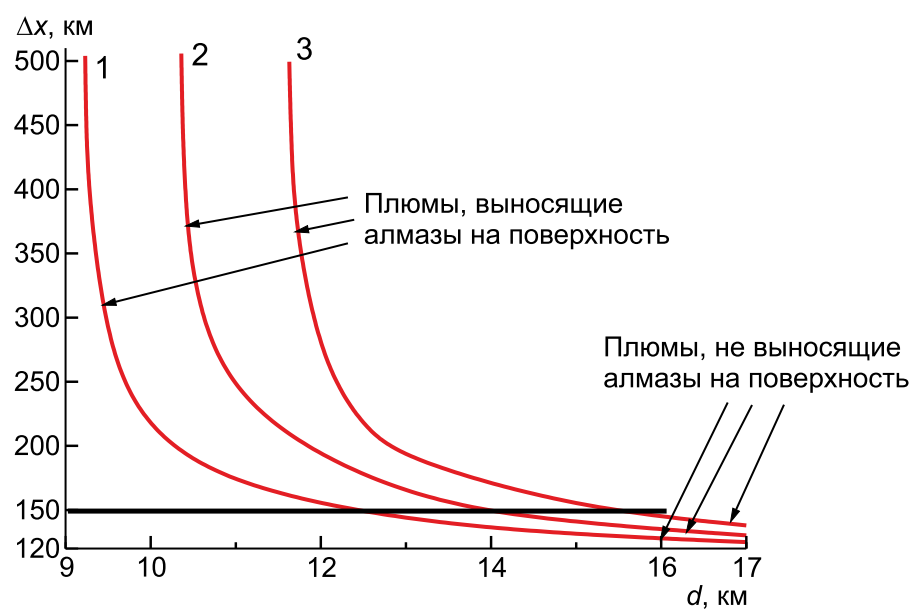

Рис. 6. Зависимость глубины $\Delta x$, с которой расплав из канала плюма выносится на поверхность, от диаметра $d$ для различных значений $v$. Прямая $\Delta x=150$ км отмечает глубину, начиная с которой алмаз устойчив [Kennedy C.S., Kennedy G.C., 1976]. Эта прямая разграничивает область алмазоносных и неалмазоносных плюмов (плюмов с грибообразной головой). 1 - v=0.5 $\mathrm{m}^{2} / \mathrm{c}$; $2-v=1 \mathrm{~m}^{2} / \mathrm{c} ; 3-\mathrm{v}=2 \mathrm{~m}^{2} / \mathrm{c}$.

Fig. 6. Depth $\Delta x$ (from which the melt is transported through the plume conduit to the surface) vs. diameter $d$ for different values of $v$. Straight line $\Delta x=150 \mathrm{~km}$ marks the depth below which diamond is stable [Kennedy C.S., Kennedy G.C., 1976] and separates the domains of diamondiferous and non-diamondiferous plumes (plumes with mushroom-shaped heads). $1-v=0.5 \mathrm{~m}^{2} / \mathrm{s} ; 2-\mathrm{v}=1 \mathrm{~m}^{2} / \mathrm{s}$; $3-v=2 \mathrm{~m}^{2} / \mathrm{s}$.

содержать алмазы. Соответственно, участки кривых 1-3, лежащие ниже границы 150 км, относятся к плюмам, которые не транспортируют алмазы к поверхности и образуют грибообразную голову.

Мы полагаем, что алмаз выносится с глубины, большей 150 км, в той же среде (расплаве), в которой он существовал, поэтому до выхода на поверхность за время, составляющее несколько десятков часов, с ним не произойдет никаких существенных изменений. Однако при выносе на поверхность он сгорит, если не будет изолирован от воздействия кислорода воздуха, поэтому, находясь в расплаве, который внедряется в кору в виде даек или каналов излияния, алмаз будет охлаждаться и может сохраняться в отсутствие окислительной среды [Kirdyashkin A.A., Kirdyashkin A.G., 2016].

Как следует из вышеприведенных оценок объема излияний, алмазоносные плюмы при относительно небольших диаметрах канала плюма (10-14 км) выносят на поверхность с больших глубин объемы расплава до $5 \cdot 10^{4}$ км$^{3}$. Вынос достаточно большого объема расплава может вызвать значительные возмущения гидродинамической структуры течения у подошвы плюма во внешнем жидком ядре. Это, в свою очередь, может нарушить процесс поступления легких компонентов от подошвы в канал плюма, что повлечет за собой повышение температуры плавления в окрестности подошвы плюма и прекращение его «работы». Таким образом, после излияния расплава можно ожидать прекращения деятельности алмазоносного плюма.

\section{5. ЭКСПЕРИМЕНТАЛЬНАЯ УСТАНОВКА ДЛЯ МОДЕЛИРОВАНИЯ ТЕЧЕНИЯ В ОБЛАСТИ СОПРЯЖЕНИЯ КАНАЛА ПЛЮМА С КАНАЛОМ ИЗЛИЯНИЯ}

Теперь представим результаты экспериментального моделирования гидродинамической структуры течения в канале термохимического плюма у его кровли и в области сопряжения канала плюма с каналом излияния.

На рис. 7 изображена схема экспериментальной установки. За основу установки брался сосуд 1 из молибденового стекла с внешним диаметром 86 мм и толщиной стенок 3 мм, имеющий рабочую длину 443.5 мм. На дно сосуда плотно устанавливался диск 7 из особо прочного пенопласта толщиной 10 мм для формирования плоского дна. Во внешний сосуд вставлялся внутренний рабочий цилиндр 2 из оптического кварца, с внешним диаметром 62 мм и толщиной стенок 4 мм. Прозрачный оптический кварц выбирался для лучшей визуализации гидродинамической структуры в процессе эксперимента.

На пенопластовое дно устанавливались узкие, но прочные распорки из винипласта 10, позволяющие зафиксировать строго по центру и соосно внутренний рабочий цилиндр 2 и в то же время осуществлять свободный ток жидкости между нижним торцом рабочего цилиндра и плоским пенопластовым основанием. Величина зазора составляла 9 мм. Сверху надевалась выточенная из оргстекла фигурная пробка 3 с проточенными пазами, для фиксации соосно внутреннего рабочего цилиндра. Фасонная пробка плотно входила во внешний контейнер на глубину 15 мм. Для подачи рабочей жидкости в экспериментальный объем в верхней фигурной пробке устанавливались капиллярные патрубки из нержавеющей стали диаметром 6 мм $(5,9)$ и 5 мм $(6)$ и толщиной стенок 0.5 мм. Патрубки 5 и 9 внутри цилиндра фиксировались по нижнему срезу пробки, а сверху возвышались на 15 мм для подключения технологических шлангов из силикона. Между внутренней стенкой наружного цилиндра и внешней стенкой рабочего цилиндра устанавливались патрубки 6 диаметром 5 мм. Патрубки диаметром 6 мм устанавливали по оси цилиндра и непосредственно у внутренней стенки 


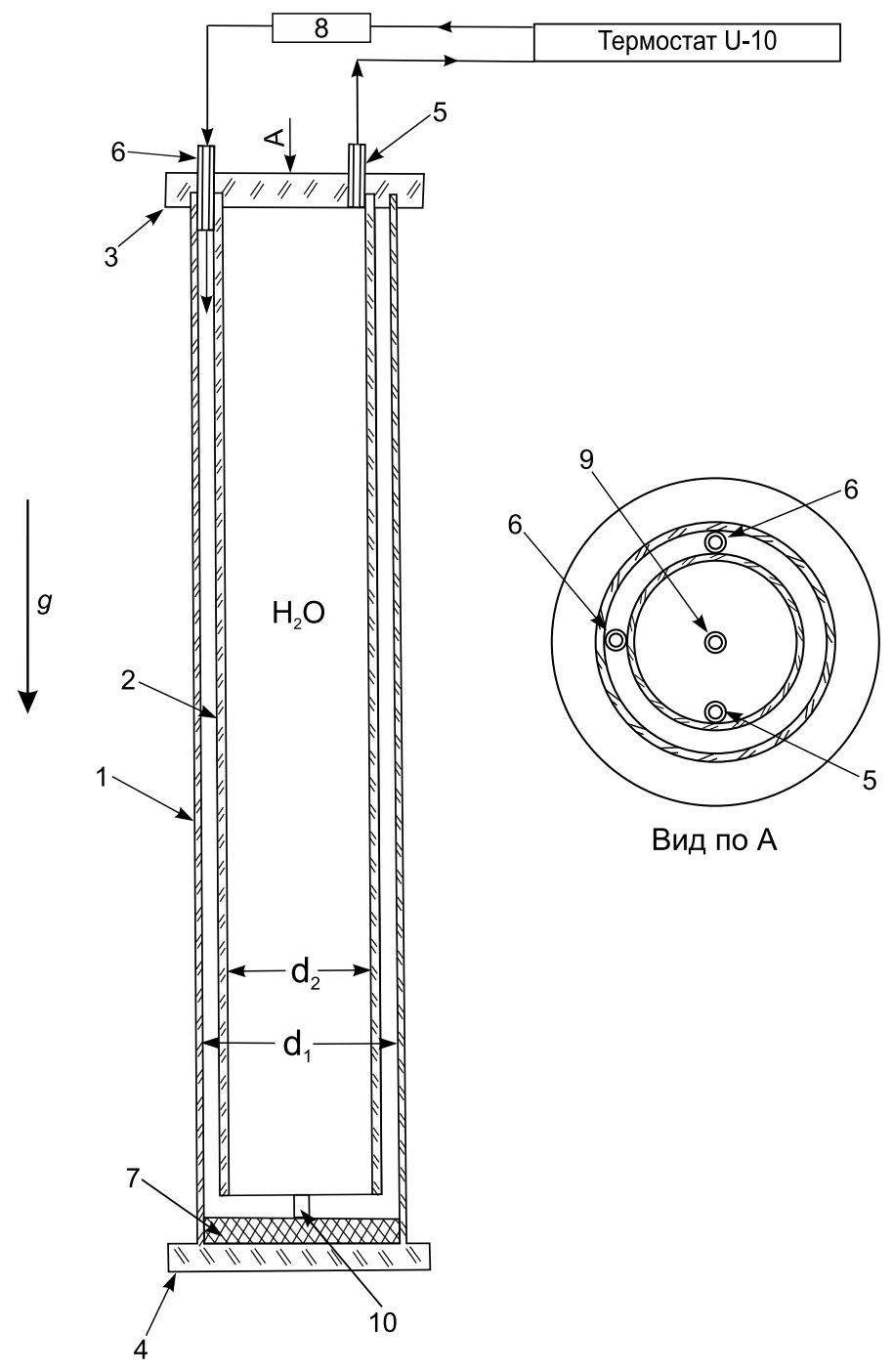

Рис. 7. Схема экспериментальной установки.

Fig. 7. Scheme of the experimental set-up.

рабочего цилиндра. Патрубки, расположенные между внутренней стенкой внешнего цилиндра и внешней стенкой рабочего цилиндра, предназначались для принудительного подвода рабочей жидкости, патрубки, расположенные в объеме внутреннего цилиндра, - для отвода рабочей жидкости. После сборки системы все стыки пазов пробки, торцевые стыки и места внешних выходов металлических капилляров герметизировались специальными водонерастворимыми герметиками. После застывания герметика система проверялась на герметичность, чтобы исключить возможность подсоса воздуха в систему.

В качестве рабочей жидкости в экспериментальном объеме использовалась дистиллированная вода. При заполнении водой экспериментальный объем устанавливался в строго вертикальном положении, чтобы избежать образования воздушных пузырей. Заполнение дистиллированной во- дой происходило через капилляр, расположенный между стенками цилиндров. Все дополнительные капилляры, кроме центрального по оси цилиндров (9), закрывались плотно притертыми пробками. Принудительное заполнение сосуда водой производилось до истечения воды через центральный патрубок и последующей герметизации входного и выходного патрубков. Далее рабочий объем устанавливался на физический стол, на специально изготовленные подставки. Источником рабочей жидкости являлся ультратермостат U-10, заполненный дистиллированной водой. Дистиллированная вода с помощью насоса термостата прокачивалась по замкнутому контуру экспериментальной установки. Для исключения попадания газа в рабочий объем устанавливался специальный газоотстойник 8. Для визуализации течений в экспериментальном объеме в воду добавлялась отсеянная мелкодисперсная алюминиевая пудра. Освещение объема рабочей жидкости осуществлялось плоским световым лучом, в качестве источника света использовались светодиодные осветители. Фотографирование гидродинамических структур проводилось фотокамерой Canon EOS 500D. В качестве канала, отводящего воду из рабочего объема, использовался капилляр, расположенный у внутренней стенки внутреннего рабочего цилиндра (5) или по центру цилиндра (9).

Задача лабораторного моделирования состояла в изучении структуры течения в области скачкообразного изменения диаметров сопряженных каналов на порядок и более. Кроме того, необходимо было выяснить, существует ли застойная зона вблизи кровли плюма и, в случае существования такой зоны, определить структуру течения в ней.

\section{6. СТРУКТУРА ТЕЧЕНИЯ В КАНАЛЕ АЛМАЗОНОСНОГО ПЛЮМА В ПЕРИОД ИЗЛИЯНИЯ РАСПЛАВА}

Как указано в разделе 3, прорыв расплава из канала плюма на поверхность происходит под воздействием силы сверхлитостатического давления на кровлю плюма. Наибольшее касательное напряжение достигается на боковой поверхности цилиндрического массива над кровлей плюма (при $r=R$ ). В этой области при достижении критического касательного напряжения образуется канал излияния, поэтому в лабораторной модели канал истечения, моделирующий канал излияния плюма, располагали у образующей стенки рабочего цилиндра. Отношение диаметров канала рабочего цилиндра $d$ (канала плюма) и канала истечения $d_{\text {к }}$ : $d / d_{\text {к }}=54$ мм $/ 5$ мм $=10.8$. Эксперименты проводились для различных значений числа Рейнольдса $\operatorname{Re}=\bar{u} d / v$, где $\bar{u}$ - скорость течения жидкости, 


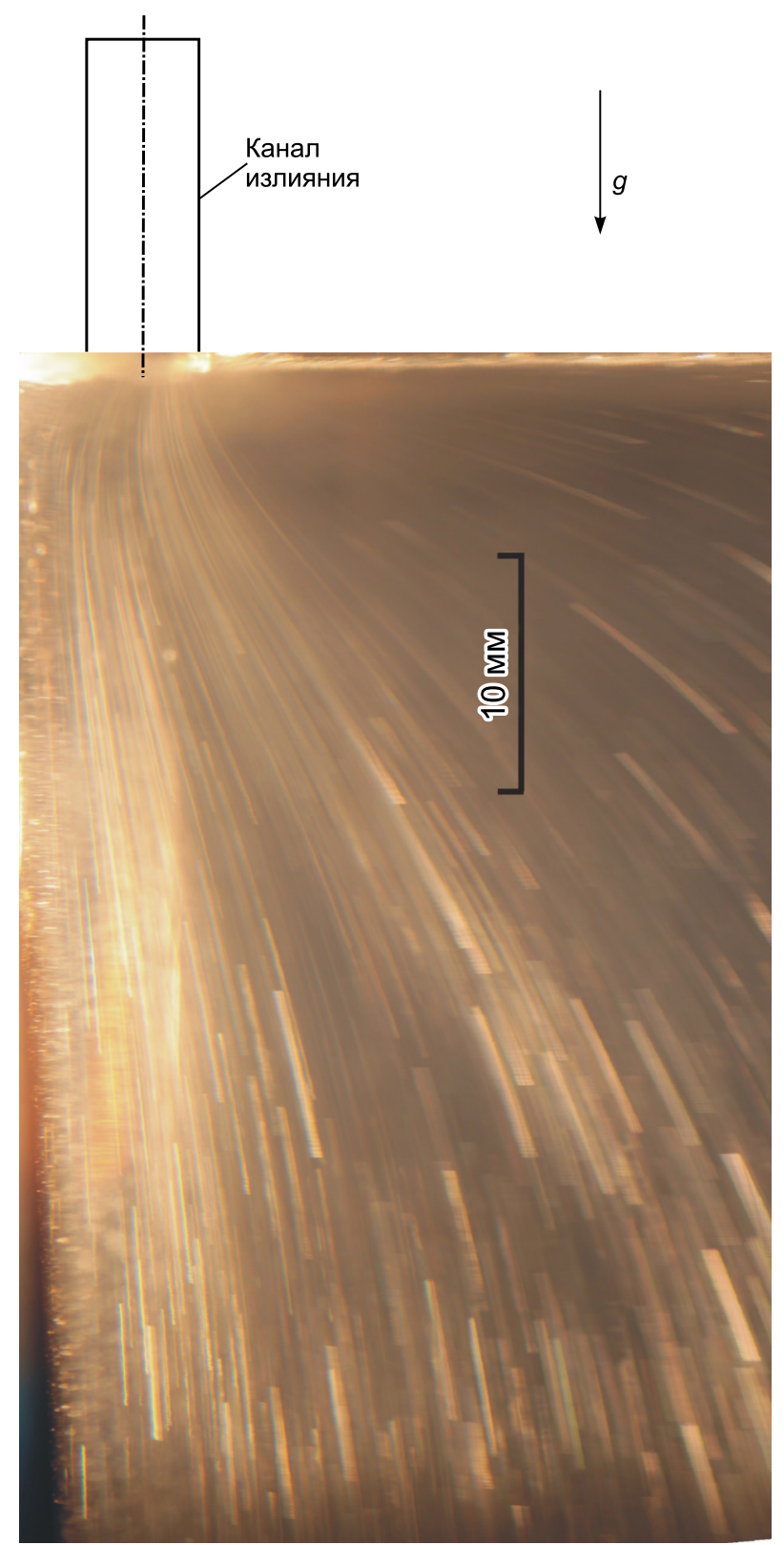

Рис. 8. Картина течения в осевой плоскости. Канал истечения расположен у образующей основного цилиндрического канала (канала плюма). $\operatorname{Re}=216, \bar{u}=4$ мм/с, время экспозиции $1 / 3$ с.

Fig. 8. Simulated flow in the axial plane. The eruption conduit is at the sidewall of the main cylindrical conduit (plume conduit). $\operatorname{Re}=216 ; \bar{u}=4 \mathrm{~mm} / \mathrm{s}$; exposure time is $1 / 3 \mathrm{~s}$.

усредненная по поперечному сечению рабочего цилиндра, v - кинематическая вязкость воды $\left(v=10^{-6} \mathrm{M}^{2} / \mathrm{c}\right)$. Лабораторное моделирование проводилось в условиях ламинарного режима течения в канале плюма $(\operatorname{Re}<2000)$.

Скорость усреднялась по фотографиям картины течения, которая при малом времени экспозиции представлялась в виде треков (рис. 8). На фотографии (рис. 8) в осевой плоскости представлено те- чение $(\mathrm{Re}=216)$ у входа в канал истечения, расположенный вблизи стенки основного цилиндрического канала. На рис. 9 представлена картина течения $(\mathrm{Re}=443)$ у торца большого цилиндрического канала, где у образующей этого канала расположен канал истечения, моделирующий канал излияния плюма. Уже при $\mathrm{Re}=443$ в цилиндрическом канале фиксируется неустойчивость течения. Наблюдается застойная область замедленного течения, в которой также наблюдается неустойчивый характер течения (рис. 9). Застойная зона находится в области сопряжения стенки канала и торца, моделирующего кровлю плюма. Скорость течения в застойной зоне составляет 0.3-0.7 мм/с. Размеры катетов застойной области $0.4 d \times 0.75 d$.

Из фотографии (см. рис. 8), снятой при относительно малом времени экспозиции (1/3 c), определены профили скорости вдоль линий тока при раз-

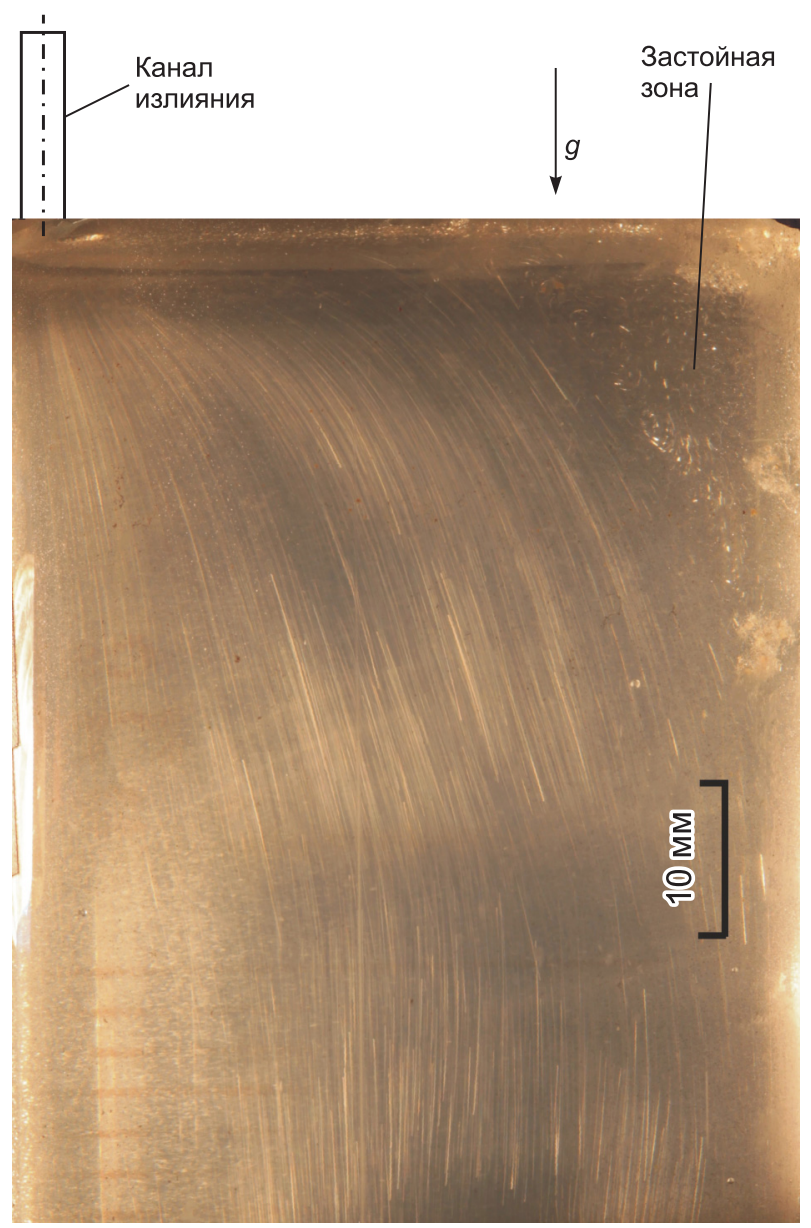

Рис. 9. Фотография картины течения в осевой плоскости. Канал истечения расположен у образующей цилиндра. $\operatorname{Re}=443, \bar{u}=8.2$ мм/с, время экспозиции 1.6 с.

Fig. 9. Simulated flow in the axial plane. The eruption conduit is at the sidewall of the main cylindrical conduit. $\operatorname{Re}=443 ; \bar{u}=8.2 \mathrm{~mm} / \mathrm{s}$; exposure time is $1.6 \mathrm{~s}$. 


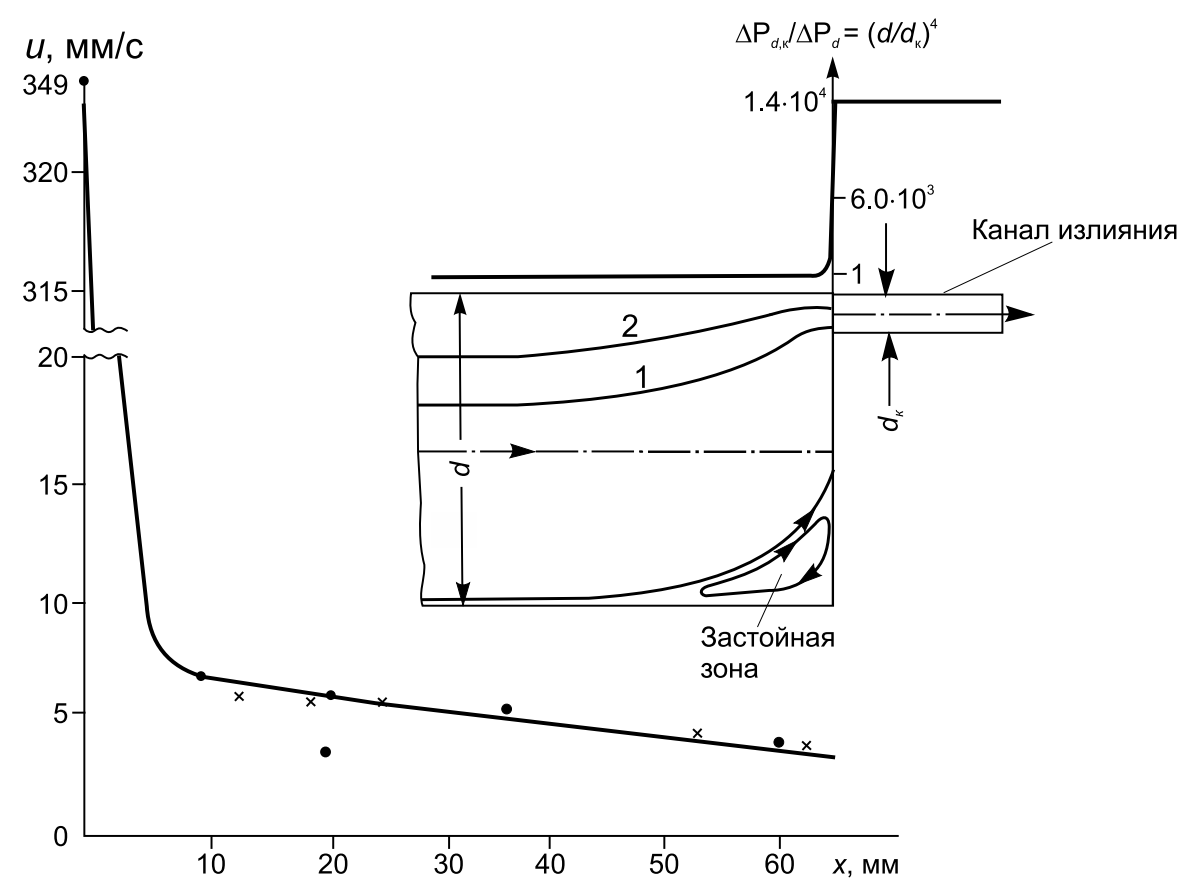

Рис. 10. Изменение скорости течения вдоль линий тока 1 и 2 в осевой плоскости. $\operatorname{Re}=216, \bar{u}=4$ мм/с; $x-$ координата вдоль линий тока, $x=0$ на входе в канал истечения; скорость $\bar{u}$ измерена на удалении от канала истечения, где линии тока становятся параллельными; $y_{\propto}$ - вертикальная координата, для которой измерена скорость $\bar{u}$. $1(\bullet)-y_{\propto}=19.5$ мм, $2(\times)-y_{\propto}=11.7$ мм.

Fig. 10. Changes in the flow streamline velocity for streamlines 1 and 2 in the axial plane. $\operatorname{Re}=216 ; \bar{u}=4 \mathrm{~mm} / \mathrm{s} ; x$ is the coordinate along the streamlines; $x=0$ at the inlet of the eruption conduit.Velocity $\bar{u}$ is measured at a distance from the eruption conduit, where the streamlines become parallel. $y_{\propto}$ is the vertical coordinate, for which velocity $\bar{u}$ is measured. $1(\bullet)-y_{\propto}=19.5 \mathrm{~mm} ; 2(x)-y_{\propto}=11.7 \mathrm{~mm}$.

личных значениях Re (рис. 10). Согласно уравнению неразрывности, $\bar{u}\left(\pi d^{2} / 4\right)=\bar{u}_{\mathrm{K}}\left(\pi d_{\mathrm{K}}^{2} / 4\right)$, где $\bar{u}_{\mathrm{K}}-$ скорость течения, усредненная по поперечному сечению канала истечения. Тогда $\bar{u}_{\mathrm{K}}=\bar{u}\left(d^{2} / d_{\mathrm{K}}^{2}\right)$, т.е.

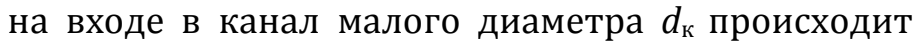
увеличение скорости $\bar{u}$ до $\bar{u}_{\text {к. }}$ В нашем случае $\bar{u}_{\kappa}=117 \bar{u}$, т.е. скорость увеличивается до значений $\bar{u}_{\mathrm{\kappa}}=349 \mathrm{Mм} / \mathrm{c}$ (рис. 10).

Увеличение скорости до значений $\bar{u}_{k}$ сопровождается потерей напора в цилиндрическом канале на величину $\Delta P_{d}=\rho \bar{u}_{\mathrm{\kappa}}{ }^{2} / 2$ ( $\rho-$ плотность жидкости) и возрастанием динамического напора в канале малого диаметра (канале истечения): $\Delta P_{d, \mathrm{\kappa}}=(\rho / 2)\left(d / d_{\mathrm{\kappa}}\right)^{4} \bar{u}^{2}$. В нашем случае происходит возрастание динамического давления в канале малого диаметра $d_{\mathrm{\kappa}}$ в $1.4 \cdot 10^{4}$ раз по сравнению с динамическим давлением в канале большого диаметpa $d$ (рис. 10). Принимаем значения $d_{\mathrm{K}}$ с учетом размеров для кимберлитовых трубок, оцененных на основе геологических и геофизических данных (например [Atikinson, Pryde, 2006; Jaques, 1998; Field et al., 2008]), $d_{\mathrm{K}}=400-1200$ м. Принимая диаметр канала плюма $d=12 \cdot 10^{3}$ м, получаем отношение $d / d_{\mathrm{K}}=10-30$. В этом случае динамическое давление в канале излияния возрастает в $10^{4}-8.1 \cdot 10^{5}$ раз. Та- ким образом, при исследовании процессов излияния магмы на поверхность следует учитывать все составляющие давления: кроме статического давления (суммы литостатического и сверхлитостатического давления) требуется учет и динамического давления $\rho u^{2} / 2$.

В системе сопряженных каналов различного диаметра, как показывает лабораторное моделирование, следует учитывать и затраты напора (сверхлитостатического давления) на увеличение скорости течения в канале меньшего диаметра, т.е. на создание динамического давления, поэтому при определении скорости течения расплава в канале излияния постоянного диаметра сверхлитостатическое давление на кровле плюма $\Delta P$ будет равно потере напора на преодоление сопротивления на стенке канала излияния $\Delta P_{\text {тр }}$ и на генерацию динамического давления (динамического напора) $\Delta P_{\mathrm{d}, \kappa}$ обусловленного кинетической энергией движущегося расплава:

$$
\Delta P_{\mathrm{K}}=\Delta P=\Delta P_{\mathrm{Tp}}+\Delta P_{\mathrm{d}, \mathrm{K}}
$$

где $\Delta P_{\text {к }}$ - перепад давления в канале излияния. В отличие от канала излияния, потерей напора на 


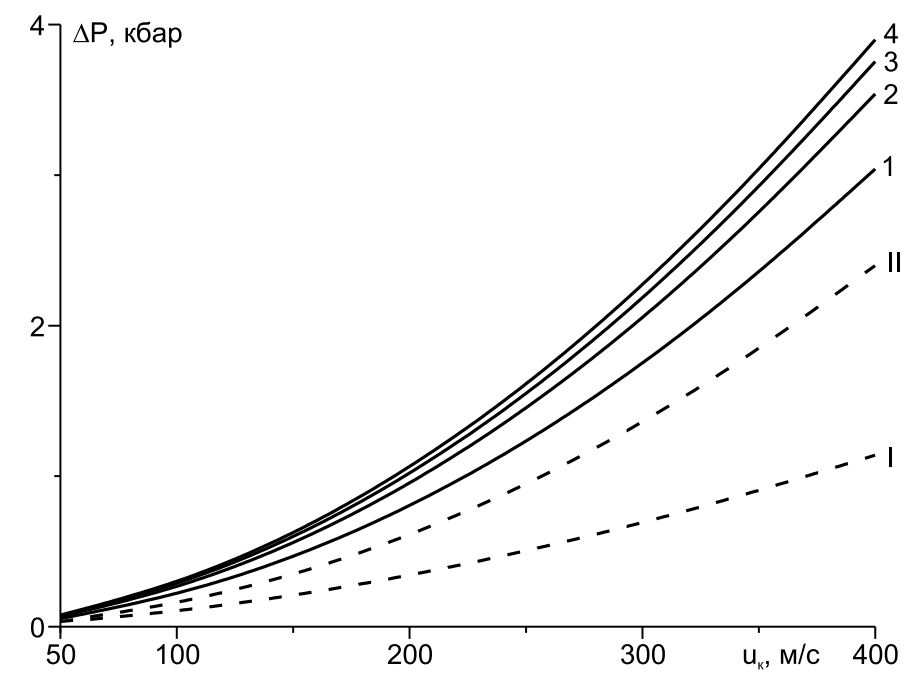

Рис. 11. Зависимость между сверхлитостатическим давлением у кровли плюма $\left(\Delta P=\Delta P_{\mathrm{Tp}}+\Delta P_{\mathrm{d}, \mathrm{\kappa}}\right)$ и скоростью течения расплава в канале излияния $\left(u_{\kappa}\right)$ для различных значений кинематической вязкости расплава $\left(v_{\kappa}\right)$. Показаны кривые для напора, затрачиваемого на преодоление трения расплава о стенки канала излияния $\left(\Delta P_{\text {тр }}\right)$, и напора, затрачиваемого на увеличение динамического давления в канале излияния $\left(\Delta P_{\mathrm{d}, \mathrm{K}}\right) .1-v_{\mathrm{K}}=0.1 \mathrm{~m}^{2} / \mathrm{c}$; $2-v_{\mathrm{K}}=1 \mathrm{M}^{2} / \mathrm{c} ; 3-v_{\mathrm{K}}=2 \mathrm{M}^{2} / \mathrm{c} ; 4-v_{\mathrm{K}}=3 \mathrm{M}^{2} / \mathrm{c} ; \mathrm{I}-\Delta \mathrm{P}_{\text {тр }}$ для $v_{\mathrm{K}}=1 \mathrm{M}^{2} / \mathrm{c}$; II- $\Delta \mathrm{P}_{\mathrm{d}, \mathrm{\kappa}}$ для $v_{\mathrm{K}}=1 \mathrm{M}^{2} / \mathrm{c}$.

Fig. 11. The relationship between the superlithostatic pressure at the plume roof $\left(\Delta P=\Delta P_{\mathrm{Tp}}+\Delta P_{\mathrm{d}, \mathrm{K}}\right)$ and the melt flow velocity in the eruption conduit $\left(u_{\mathrm{K}}\right)$ for different kinematic viscosities of melt $\left(v_{\mathrm{K}}\right)$. Curves show the frictional pressure drop $\left(\Delta P_{\text {тр }}\right)$ and the increasing dynamic pressure in the eruption conduit $\left(\Delta P_{\mathrm{d}, \mathrm{K}}\right) .1-v_{\mathrm{K}}=0.1 \mathrm{~m}^{2} / \mathrm{s} ; 2-v_{\mathrm{K}}=1 \mathrm{~m}^{2} / \mathrm{s}$; $3-v_{\mathrm{K}}=2 \mathrm{~m}^{2} / \mathrm{s} ; 4-v_{\mathrm{K}}=3 \mathrm{~m}^{2} / \mathrm{s}$. I $-\Delta \mathrm{P}_{\text {тр }}$ for $v_{\mathrm{K}}=1 \mathrm{~m}^{2} / \mathrm{s} ; \mathrm{II}-\Delta \mathrm{P}_{\mathrm{d}, \mathrm{K}}$ for $v_{\mathrm{K}}=1 \mathrm{~m}^{2} / \mathrm{s}$.

трение в канале плюма из-за его малости пренебрегаем [Kirdyashkin A.A., Kirdyashkin A.G., 2016].

Перейдем к рассмотрению излияния расплава из канала прорыва. При турбулентном режиме течения перепад давления по длине канала излияния из-за трения $\Delta P_{\text {тр }}$, для гладкого цилиндрического канала, согласно [Schlichting, 1979],

$$
\Delta P_{\mathrm{Tp}}=0.1582 \bar{u}_{\mathrm{\kappa}}{ }^{7 / 4} v_{\mathrm{\kappa}}^{1 / 4} \rho_{\mathrm{\kappa}} x_{\mathrm{\kappa p}} / d_{\mathrm{\kappa}}^{5 / 4},
$$

где $\bar{u}_{\kappa}$ - скорость течения расплава в канале излияния, усредненная по его поперечному сечению, $v_{\kappa}-$ кинематическая вязкость, $\rho_{к}$ - плотность расплава в канале излияния. Динамическое давление в канале излияния постоянного диаметра [Schlichting, 1979]

$$
\Delta P_{\mathrm{d}, \mathrm{\kappa}}=\rho_{\mathrm{K}} \bar{u}_{\mathrm{\kappa}}^{2} / 2 .
$$

Перепад давления в канале излияния равен сверхлитостатическому давлению на кровле плюма, и с учетом соотношений (18)-(20)

$$
\begin{aligned}
& \Delta P_{\mathrm{K}}=\Delta P= \\
& =0.1582 \bar{u}_{\mathrm{K}}^{7 / 4} v_{\mathrm{K}}^{1 / 4} \rho_{\mathrm{K}} x_{\mathrm{\kappa p}} / d_{\mathrm{K}}^{5 / 4}+\rho_{\mathrm{K}} \bar{u}_{\mathrm{K}}^{2} / 2 .
\end{aligned}
$$

Давление в расплаве под кровлей плюма, поднимающегося (выплавляющегося) от границы ядро мантия, превышает литостатическое давление пород над кровлей плюма на величину $\Delta P$, определяемую соотношением (3).

С использованием соотношения (21) представлена зависимость между сверхлитостатическим давлением у кровли плюма $\Delta P$ и скоростью течения расплава в канале излияния $u_{\text {к }}$ (рис. 11). Кривые 1-4 построены для кинематической вязкости расплава $v_{\kappa}=0.1-3.0 \mathrm{~m}^{2} / \mathrm{c}$ и диаметра канала излияния $d_{\kappa}=400$ м. Сверхлитостатическое давление на кровле плюма $\Delta P$ вызывает движение расплава в канале излияния, т.е. является движущим напором. Кроме движущего напора $\Delta P$, для $v_{\kappa}=1 \mathrm{~m}^{2} /$ с показаны величины напора $\Delta P_{\text {тр }}$, расходуемого на преодоление трения расплава о стенки канала (кривая I), и напора $\Delta P_{\mathrm{d}, \mathrm{\kappa}}$, расходуемого на увеличение динамического давления в канале излияния (кривая II). Согласно оценкам, полученным в разделе 3 , величина сверхлитостатического давления $\Delta P \approx 1-4$ кбар. Для $v_{\kappa}=0.1-3.0 \mathrm{M}^{2} /$ с при давлении $\Delta P=1$ кбар скорость течения расплава в канале излияния $u_{\mathrm{\kappa}}=193-$ 225 м/с, при давлении $\Delta P=3$ кбар, $u_{\kappa}=349-398$ м/с. Давлению $\Delta P=4$ кбар соответствует скорость $u_{\mathrm{K}}=400 \mathrm{~m} / \mathrm{c}$ для $v_{\mathrm{K}}=3 \mathrm{M}^{2} / \mathrm{c}$.

\section{7. ЗАКЛЮЧЕНИЕ}

Термохимические мантийные плюмы промежуточной тепловой мощности $\left(1.6 \cdot 10^{10} \mathrm{BT}<N<\right.$ $<2.7 \cdot 10^{10}$ Вт) формируются на границе ядро - мантия под кратонами в условиях слабых горизонтальных свободно-конвективных течений в мантии. В вертикальном сечении канал плюма промежуточной мощности представляет собой систему конвективных ячеек, разделенных областями сужения. Вдоль области восходящего потока канала происходит плавление, вдоль нисходящего потока - кристаллизация на границе и в областях сужения канала (при уменьшении его диаметра). При относительной тепловой мощности $1.15<\mathrm{Ka}<$ $<1.9\left(1.6 \cdot 10^{10} \mathrm{Bт}<N<2.7 \cdot 10^{10}\right.$ Вт) плюм прорывается на поверхность. Давление в расплаве под кровлей поднимающегося (выплавляющегося) плюма превышает литостатическое давление над кровлей плюма на величину $\Delta P$. Перепад давления $\Delta P$ зависит от разности температур расплава в канале плюма и окружающей мантии и от отношения диаметра сужения к диаметру канала плюма. Установлены условия излияния расплава, образо- 
ванного плюмом, на поверхность. Сила давления $F=\Delta P\left(\pi d^{2} / 4\right)$ на кровлю поднимающегося плюма диаметром $d$ вызывает движение в массиве коры, находящемся над кровлей. При уменьшении высо-

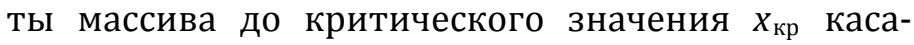
тельное напряжение на боковой поверхности мас-

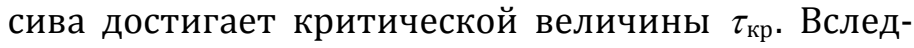
ствие разрушения пород массива образуется канал

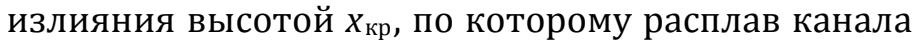
плюма прорывается на поверхность. Высота канала излияния $x_{\text {кр }}$ может составлять от 9.2 до 13.5 км для диаметра $d=10-17$ км.

Как показывают ранее проведенные нами эксперименты, излияние расплава из канала термохимического плюма происходит в две стадии. На первой стадии объем расплава, изливающегося из верхней части плюма, равен объему расплава, накопившегося у подошвы плюма в период его подъема до уровня $X_{\text {кр }}$. При прорыве плюма на поверхность расплав, скопившийся у подошвы плюма, поднимается в его канал. Сразу же после первой стадии излияния от подошвы плюма в его канал поднимается вещество жидкого внешнего ядра и из верхней части плюма изливается расплав, выдавленный из канала плюма веществом внешнего ядра, поднявшимся в канал. Объем излившегося магматического расплава есть сумма объемов излияний для первой $\left(V_{1}\right)$ и второй $\left(V_{2}\right)$ стадии. Объем $V_{1}$ можно получить, используя тепловую мощность и время подъема плюма. Объем $V_{2}$ можно найти, используя высоту подъема веще-

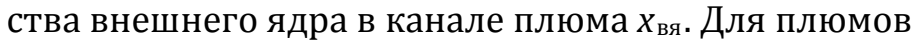
промежуточной тепловой мощности объем излияний может составлять от $1.3 \cdot 10^{4}$ до $5 \cdot 10^{4} \mathrm{KM}^{3}$. Глубина $\Delta x$, с которой расплав был вынесен из канала плюма на поверхность, определяется отношением объема излияний к диаметру канала плюма. В том случае, когда $\Delta x>150$ км, расплав из канала плюма может доставлять алмазы на поверхность. Такие плюмы можно назвать алмазоносными. При $\Delta x<150$ км плюмы не транспортиру- ют алмазы к поверхности. Это плюмы с грибообразной головой, для которых относительная тепловая мощность Ка>1.9 (N>2.7•1010 Вт).

Представлены результаты лабораторного моделирования структуры течения в области сопряжения канала алмазоносного плюма и канала излияния для отношения диаметров $d / d_{\kappa}=10.8$, где $d_{\text {к }}-$ диаметр канала излияния. Эксперименты показали наличие застойной зоны, которая находится в области сопряжения стенки канала плюма и торца, моделирующего кровлю плюма. Размеры катетов застойной области $0.4 d \times 0.75 d$. Скорость течения в застойной зоне в десятки раз меньше, чем скорость течения в канале плюма у входа в канал излияния.

В лабораторном эксперименте динамическое давление в канале излияния возрастает в $14 \cdot 10^{3}$ раз по сравнению с таковым в канале плюма. Оценки для алмазоносных плюмов показали, что при отношении $d / d_{\kappa}=10-30$ динамическое давление в канале излияния возрастает в $10^{4}-8.1 \cdot 10^{5}$ раз. Сверхлитостатическое давление в канале плюма $\Delta P$ равно сумме напора, расходуемого на преодоление трения расплава о стенки канала $\left(\Delta P_{\text {тр }}\right)$, и напора, расходуемого на увеличение динамического давления $\left(\Delta P_{\mathrm{d}, \mathrm{\kappa}}\right)$ в канале излияния. Получено соотношение, связывающее скорость течения расплава в канале излияния $u_{к}$ и сверхлитостатическое давление у кровли плюма. При увеличении

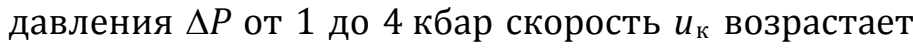
от 200 до 400 м/с.

\section{8. БЛАГОДАРНОСТИ}

Работа выполнена по государственному заданию ИГМ СО РАН. Финансирующая организация: Министерство науки и высшего образования Российской Федерации. Авторы благодарны двум анонимным рецензентам за конструктивные отзывы.

\section{9. ЛИTEPATУPA / REFERENCES}

Atikinson E., Pryde R., 2006. Seismic Investigation of Selected Kimberlite Pipes in the Buffalo Head Hills Kimberlite Field, North-Central Alberta. Alberta Energy and Utilities Board, EUB/AGS Special Report 079, 5 p.

Azhgirey G.D., 1956. Structural Geology. Moscow State University Publishing House, Moscow, 492 p. (in Russian) [Ажгирей Г.Д. Структурная геология. М.: Изд-во МГУ, 1956. 492 с.].

Chalapathi Rao N.V., Lehmann B., 2011. Kimberlites, flood basalts and mantle plumes: New insights from the Deccan Large Igneous Province. Earth-Science Reviews 107 (3-4), 315-324. https://doi.org/10.1016/j.earscirev.2011. 04.003.

Davaille A., Limare A., Touitou F., Kumagai I., Vatteville J., 2011. Anatomy of a laminar starting thermal plume at high Prandtl number. Experiments in Fluids 50 (2), 285-300. https://doi.org/10.1007/s00348-010-0924-y.

Dawson J.B., 1980. Kimberlites and Their Xenoliths. Springer-Verlag, Berlin-Heidelberg, 252 р. [Русский перевод: Доусон Дж. Кимберлиты и ксенолиты в них. М.: Мир, 1983. 300 с.]. 
Dobretsov N.L., Kirdyashkin A.A., Kirdyashkin A.G., Vernikovsky V.A., Gladkov I.N., 2008. Modelling of thermochemical plumes and implications for the origin of the Siberian traps. Lithos 100 (1-4), 66-92. https://doi.org/10.1016/ j.lithos.2007.06.025.

Dobretsov N.L., Kirdyashkin A.G., Kirdyashkin A.A., 2001. Deep-Level Geodynamics. Siberian Branch of RAS Publishing House, Geo Branch, Novosibirsk, 408 p. (in Russian) [Добрецов Н.Л., Кирдяшкин А.Г., Кирдяшкин А.А. Глубинная геодинамика. Новосибирск: Изд-во СО РАН, филиал «Гео», 2001. 408 с.].

Fedortchouk Y., Matveev S., Carlson J.A., 2010. $\mathrm{H}_{2} \mathrm{O}$ and $\mathrm{CO}_{2}$ in kimberlitic fluid as recorded by diamonds and olivines in several Ekati Diamond Mine kimberlites, Northwest Territories, Canada. Earth and Planetary Science Letters 289 (3-4), 549-559. https://doi.org/10.1016/j.epsl.2009.11.049.

Field M., Stiefenhofer J., Robey J., Kurszlaukis S., 2008. Kimberlite-hosted diamond deposits of southern Africa: A review. Ore Geology Reviews 34 (1-2), 33-75. https://doi.org/10.1016/j.oregeorev.2007.11.002.

Gladkov I.N., Distanov V.E., Kirdyashkin A.A., Kirdyashkin A.G., 2012. Stability of a melt/solid interface with reference to a plume channel. Fluid Dynamics 47 (4), 433-447. https://doi.org/10.1134/S0015462812040023.

Jaques A.L., 1998. Kimberlite and lamproite diamond pipes. AGSO Journal of Australian Geology and Geophysics 17 (4), 153-162.

Jaupart C., Mareschal J.-C., 2007. Heat flow and thermal structure of the lithosphere. In: G. Schubert (Ed.), Treatise on geophysics. Vol. 6. Crust and lithosphere dynamics. Elsevier, Amsterdam, p. 217-251. https://doi.org/10.1016/ B978-044452748-6.00104-8.

Jaupart C., Mareschal J.-C., 2014. Constraints on crustal heat production from heat flow data. In: H. Holland, K. Turekian (Eds.), Treatise on geochemistry (Second Edition). Vol. 4. The crust. Elsevier, Amsterdam, p. 53-73. https:// doi.org/10.1016/B978-0-08-095975-7.00302-8.

Kaminski E., Jaupart C., 2003. Laminar starting plumes in high-Prandtl-number fluids. Journal of Fluid Mechanics 478, 287-298. https://doi.org/10.1017/S0022112002003233.

Kennedy C.S., Kennedy G.C., 1976. The equilibrium boundary between graphite and diamond. Journal of Geophysical Research 81 (14), 2467-2470. https://doi.org/10.1029/JB081i014p02467.

Kirdyashkin A.A., Dobretsov N.L., Kirdyashkin A.G., 2004. Thermochemical plumes. Geologiya i Geofizika (Russian Geology and Geophysics) 45 (9), 1005-1024.

Kirdyashkin A.A., Dobretsov N.L., Kirdyashkin A.G., 2009. Heat transfer between a thermochemical plume channel and the surrounding mantle in the presence of horizontal mantle flow. Izvestiya, Physics of the Solid Earth 45 (8) 684-700. https://doi.org/10.1134/S1069351309080084.

Kirdyashkin A.A., Dobretsov N.L., Kirdyashkin A.G., Gladkov I.N., Surkov N.V., 2005. Hydrodynamic processes associated with plume rise and conditions for eruption conduit formation. Geologiya i Geofizika (Russian Geology and Geophysics) 46 (9), 869-885.

Kirdyashkin A.A., Kirdyashkin A.G., 2016. On thermochemical mantle plumes with an intermediate thermal power that erupt on the Earth's surface. Geotectonics 50 (2), 209-222. https://doi.org/10.1134/S0016852116020059.

Kirdyashkin A.A., Kirdyashkin A.G., Distanov V.E., Gladkov I.N., 2016. Geodynamic regimes of thermochemical mantle plumes. Russian Geology and Geophysics 57 (6), 858-867. https://doi.org/10.1016/j.rgg.2016.05.003.

Kirdyashkin A.G., Kirdyashkin A.A., 2018. Hydrodynamics and heat and mass transfer in mushroom-shaped heads of thermochemical plumes. Geodynamics \& Tectonophysics 9 (1), 263-286 (in Russian) [Кирдяшкин А.Г., Кирдяшкин А.А. Гидродинамика и тепломассообмен в грибообразной голове термохимического плюма // Геодинамика и тектонофизика. 2018. T. 9. № 1. C. 263-286]. https://doi.org/10.5800/GT-2018-9-1-0348.

Kirdyashkin A.G., Kirdyashkin A.A., Gladkov I.N., Distanov V.E., 2012. Experimental modeling of the effect of relative thermal power on the shape of a plume conduit and the structure of free-convection flow in it. Russian Geology and Geophysics 53 (7) 689-697 https://doi.org/10.1016/j.rgg.2012.05.007.

Kotelkin V.D., Lobkovskii L.I., 2011. Thermochemical theory of geodynamical evolution. Doklady Earth Sciences 438 (1), 622-626. https://doi.org/10.1134/S1028334X11050333.

Kumagai I., Davaille A., Kurita K., 2007. On the fate of thermally buoyant mantle plumes at density interfaces. Earth and Planetary Science Letters 254 (1-2), 180-193. https://doi.org/10.1016/j.epsl.2006.11.029.

Lin S.-C., van Keken P.E., 2006. Dynamics of thermochemical plumes: 1. Plume formation and entrainment of a dense layer. Geochemistry, Geophysics, Geosystems. 7 (2), Q02006. https://doi.org/10.1029/2005GC001071.

Olson P., Singer H. 1985. Creeping plumes. Journal of Fluid Mechanics 158, 511-531. https://doi.org/10.1017/S002211 2085002749.

Schlichting H., 1979. Boundary-Layer Theory. McGraw-Hill, 817 p.

Torsvik T.H., Burke K., Steinberger B., Webb S.J., Ashwal L.D., 2010. Diamonds sampled by plumes from the core-mantle boundary. Nature 466 (7304), 352-355. https://doi.org/10.1038/nature09216.

Trubitsyn V.P., Kharybin E.V., 2010. Thermochemical mantle plumes. Doklady Earth Sciences 435 (2), 1656-1658. https://doi.org/10.1134/S1028334X10120226. 
Vatteville J., van Keken P.E., Limare A., Davaille A., 2009. Starting laminar plumes: Comparison of laboratory and numerical modeling. Geochemistry, Geophysics, Geosystems 10 (12), Q12013. https://doi.org/10.1029/2009GC00 2739.

Whitehead J.A., Luther D.S., 1975. Dynamics of laboratory diapir and plume models. Journal of Geophysical Research 80 (5), 705-717. https://doi.org/10.1029/JB080i005p00705.

Yang T., Fu R., 2014. Thermochemical piles in the lowermost mantle and their evolution. Physics of the Earth and Planetary Interiors 236, 109-116. https://doi.org/10.1016/j.pepi.2014.04.006.

Zhong S., 2006. Constraints on thermochemical convection of the mantle from plume heat flux, plume excess temperature, and upper mantle temperature. Journal of Geophysical Research: Solid Earth 111 (B4), B04409. https:// doi.org/10.1029/2005JB003972.

Анатолий Григорьевич Кирдяшкин

докт. техн. наук, в.н.с.

Институт геологии и минералогии им. В.С. Соболева СО РАН

630090, Новосибирск, пр. Академика Коптюга, 3, Россия

凶e-mail:agk@igm.nsc.ru

\section{Алексей Анатольевич Кирдяшкин}

докт. геол.-мин. наук, профессор РАН, зав. лабораторией

Институт геологии и минералогии им. В.С. Соболева СО РАН

630090, Новосибирск, пр. Академика Коптюга, 3, Россия

Новосибирский национальный исследовательский

государственный университет

630090, Новосибирск, ул. Пирогова, 2, Россия

e-mail: aak@igm.nsc.ru

\section{Валерий Элимирович Дистанов}

канд. геол.-мин. наук, с.н.с.

Институт геологии и минералогии им. В.С. Соболева СО РАН

630090, Новосибирск, пр. Академика Коптюга, 3, Россия

e-mail: dist@igm.nsc.ru

\section{Игорь Николаевич Гладков}

H.C.

Институт геологии и минералогии им. В.С. Соболева СО РАН 630090, Новосибирск, пр. Академика Коптюга, 3, Россия
Anatoly G. Kirdyashkin

Doctor of Technical Sciences, Lead Researcher

V.S. Sobolev Institute of Geology and Mineralogy, Siberian Branch of RAS 3 Academician Koptyug ave., Novosibirsk 630090, Russia

\section{Alexei A. Kirdyashkin}

Doctor of Geology and Mineralogy, Professor of RAS, Head of Laboratory

V.S. Sobolev Institute of Geology and Mineralogy, Siberian Branch of RAS 3 Academician Koptyug ave., Novosibirsk 630090, Russia

Novosibirsk State University

2 Pirogov street, Novosibirsk 630090, Russia

\section{Valery E. Distanov}

Candidate of Geology and Mineralogy, Senior Researcher

V.S. Sobolev Institute of Geology and Mineralogy, Siberian Branch of RAS 3 Academician Koptyug ave., Novosibirsk 630090, Russia

\section{Igor N. Gladkov}

Researcher

V.S. Sobolev Institute of Geology and Mineralogy, Siberian Branch of RAS 3 Academician Koptyug ave., Novosibirsk 630090, Russia

e-mail: kir@igm.nsc.ru 